Review

\title{
Development of Polymer Acceptors for Organic Photovoltaic Cells
}

\section{Yujeong Kim and Eunhee Lim *}

Department of Chemistry, Kyonggi University, San 94-6, Iui-dong, Yeongtong-gu, Suwon-si, Gyeonggi 443-760, Korea; E-Mail: yujeong-kim@kyonggi.ac.kr

* Author to whom correspondence should be addressed; E-Mail: ehlim@kyonggi.ac.kr; Tel.: +82-31-249-9663.

Received: 15 January 2014; in revised form: 6 February 2014 / Accepted: 7 February 2014 / Published: 10 February 2014

\begin{abstract}
This review provides a current status report of the various $n$-type polymer acceptors for use as active materials in organic photovoltaic cells (OPVs). The polymer acceptors are divided into four categories. The first section of this review focuses on rylene diimide-based polymers, including perylene diimide, naphthalene diimide, and dithienocoronene diimide-based polymers. The high electron mobility and good stability of rylene diimides make them suitable for use as polymer acceptors in OPVs. The second section deals with fluorene and benzothiadiazole-based polymers such as poly(9,9'-dioctylfluorene-co-benzothiadiazole), and the ensuing section focuses on the cyano-substituted polymer acceptors. Cyano-poly(phenylenevinylene) and poly(3-cyano-4-hexylthiophene) have been used as acceptors in OPVs and exhibit high electron affinity arising from the electron-withdrawing cyano groups in the vinylene group of poly(phenylenevinylene) or the thiophene ring of polythiophene. Lastly, a number of other electron-deficient groups such as thiazole, diketopyrrolopyrrole, and oxadiazole have also been introduced onto polymer backbones to induce $n$-type characteristics in the polymer.-Since the first report on all-polymer solar cells in 1995, the best power conversion efficiency obtained with these devices to date has been $3.45 \%$. The overall trend in the development of $n$-type polymer acceptors is presented in this review.
\end{abstract}

Keywords: polymer acceptors; organic photovoltaic cells; all-polymer solar cells 


\section{Introduction}

The thrust towards energy conservation has fuelled intensive research into the development of alternative energy sources. Solar energy offers the advantages of being renewable and clean, thus making solar cells attractive as a prospective alternative energy source. Photovoltaic (PV) cells based on inorganic materials are currently the main commercially used devices because of their relatively high efficiencies (e.g., 15\%-20\% for silicon-based PVs); nevertheless, these devices are limited by the high fabrication cost and related environmental issues [1-4]. Consequently, organic photovoltaic cells (OPVs) which offer the advantages of relatively low fabrication cost, easy processing, and flexibility, have gained focus despite their relatively low efficiencies [5]. The development of OPVs has progressed rapidly with the synthesis of new organic materials, control of processing condition such as annealing and the use of additive [6], as well as the introduction of various device structures such as the tandem and inverted structure [7-9]. In addition, control of morphology of active layers [10] and the development of purification by removing residual catalysts in conjugated polymers [11] have also been considered as important issues to achieve consistent, high-performance OPVs. Currently, the highest power conversion efficiency (PCE) of 12\% has been announced by Heliatek [12]. Despite the relatively low PCEs of OPVs compared to those of inorganic-based solar cells, the development of OPVs is nevertheless rapid based on the anticipation that the numerous advantages can outweigh the low PCE of OPVs.

OPVs comprise an active layer consisting of organic materials that is sandwiched between two electrodes with different work functions (e.g., indium tin oxide (ITO) and Al as anode and cathode, respectively), and interfacial (hole/electron transporting) layers can be added between both electrodes and the active layer. The active layers in OPVs are normally composed of two electron donor (D) and electron acceptor (A) materials for the generation of the Coulomb-bound electron-hole pair (exciton) by photoexcitation of the donor. The diffused excitons are separated into charges of electrons and holes on the D-A surface, followed by free charge transportation and collection at electrodes. The appropriate highest occupied molecular orbital (HOMO), lowest unoccupied molecular orbital (LUMO) energy level of the donors and acceptors, and low band-gap are known to be important for high OPV performance, as well as good film-forming properties, strong absorption ability, and high charge mobility. OPV cells have been fabricated in bi-layer and bulk-heterojuncton (BHJ) solar cells according to the configuration of the active layer. Bi-layer OPVs containing separate donor and acceptor layers were first reported by Tang in 1986 [13]; their performance is known to be limited by the small charge-generating interfacial area between the donor and acceptor layers $[14,15]$. The BHJ solar cells, developed by $\mathrm{Yu}$ and Heeger et al., can be fabricated by simple spin-coating of a blended solution of donor and acceptor, and have an interpenetrating network with a large D-A interfacial area [16]. BHJ solar cells have been extensively used in the fabrication of high efficiency OPVs, and various processing techniques have been developed to achieve good film morphology of the BHJ solar cells, such as thermal annealing and the use of small amounts of additives [17].

The material system comprising poly(3-hexylthiophene) (P3HT, D1) and [6,6]-phenyl-C61 butyric acid methylester $\left(\mathrm{PC}_{61} \mathrm{BM}\right)$ as respective electron donor and acceptor is archetypal of the active layer in OPVs (Figure 1). In recent decades, various polymeric and small-molecule electron donor and acceptor materials have been synthesized and developed to achieve high-efficiency OPV cells, with 
specific focus on the development of polymer donors with an extended conjugated system for solution-processable OPVs. At the present stage, high PCEs of up to 9.2\% have been achieved by using the polymeric donor thieno[3,4-b]thiophene/benzodithiophene (PTB7) with an inverted device structure [18]. The development of donor materials for OPVs has mainly focused on the syntheses of low-band-gap conjugated materials composed of electron-rich and electron-deficient repeating units (e.g., D-A type) for efficient absorption of the solar spectrum. Based on this synthetic design rule, a number of low-band-gap conjugated polymers (optical energy band-gap, $E_{\mathrm{g}}<1.8 \mathrm{eV}$ ) have been synthesized and employed as donors in polymer photovoltaic cells. Most building blocks for electron-rich units are based on thiophene and/or phenylene in the fused form or with bridging atoms for increased planarity of the polymer backbone and consequently enhanced short circuit current $\left(J_{\mathrm{SC}}\right)$ and PCE [19]. Examples of electron-rich units include cyclopenta[2,1-b:3,4-b']dithiophene (CPDT) [20], dithieno[3,2-b:2',3'-d]silole [21] and 5H-dithieno[3,2-b:2',3'-d]pyran (DTP) [22]. Various electron-deficient units have been copolymerized, and examples of building blocks for electron-deficient units are presented below. The development of high efficiency small-molecule donors has been the focus in more recent studies, and a high PCE of 8.12\% has been achieved using D-A type oligothiophenes with strong electron-withdrawing dye units at both ends [23]. To enhance the PCE, various polymeric and small-molecule donors have also been synthesized and developed.

Figure 1. (a) Representative device configuration of organic photovoltaic cells (OPVs) and (b) molecular structures of P3HT (D1), $\mathrm{PC}_{61} \mathrm{BM}$, and $\mathrm{PC}_{71} \mathrm{BM}$.

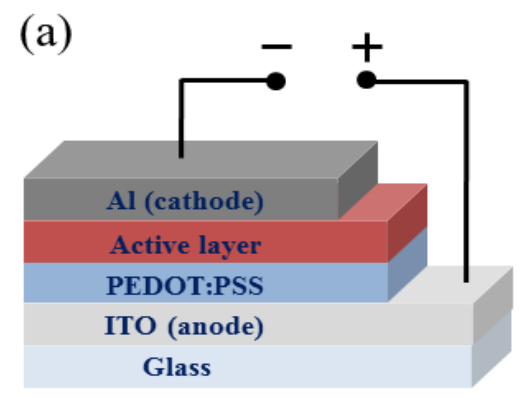

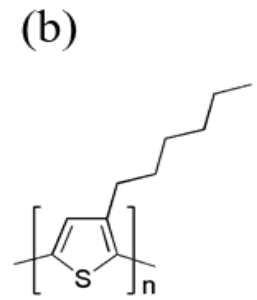

D1, P3HT

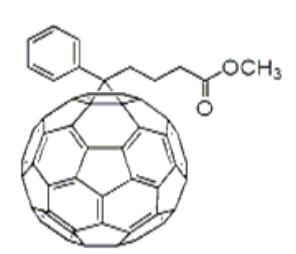

$\mathrm{PC}_{61} \mathrm{BM}$

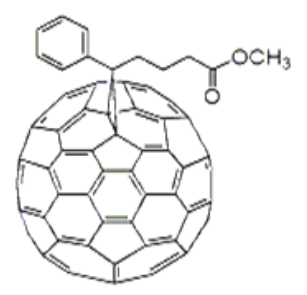

$\mathrm{PC}_{71} \mathrm{BM}$

On the other hand, fullerene derivatives such as $\mathrm{PC}_{61} \mathrm{BM}$ and $\mathrm{PC}_{71} \mathrm{BM}$ have been widely used as representative acceptor materials for obtaining high PCEs in OPVs because of their good electron mobility as $n$-type materials, adequate band-gaps, and good interaction with donor materials in OPVs. Recently, non-fullerene small-molecule acceptor materials based on strong electron-withdrawing units, which exhibited high electron mobility in organic field-effect transistor (OFET) applications, have also been reported and are discussed in other review papers [24-27]. Examples include rylene imide, metallophthalocyanins, vinazene, and diketopyrrolopyrrole (DPP) units. PCEs of 3.45\% [28] and 4.03\% [29] have respectively been achieved for OPV devices employing polymer acceptors and small-molecule acceptors. Despite their relatively low efficiencies, the polymer acceptors have some unique advantages such as high absorption coefficients in the visible spectral region and easily tunable energy levels, compared to fullerenes and non-fullerene small-molecule acceptors [30]. Furthermore, the concept of conjugated block copolymers (BCPs) has been recently introduced to combine a donor and acceptor block into a single macromolecular platform and emerged as a promising class of 
materials for OPVs [31-34]. A large scale macroscopic phase separation is impeded in the BCP due to the covalent connectivity of the two blocks and the self-assembly of BCPs into mesoscale (5-500 nm) well-ordered morphologies is ideal for the active layer of OPVs [35-37]. The performance of up to $3.1 \%$ was achieved at the present stage [38].

Herein, we focus on various polymer acceptors for all-polymer solar cells, which have been rarely reported compared to small-molecule acceptors. The polymer acceptors are categorized into four classes on the basis of their structures, i.e., rylene diimide-based polymers, fluorene- and benzothiadiazole (BT)-based polymers, cyano (CN)-substituted polymers, and other polymer acceptors containing various electron-withdrawing units.

\section{Rylene Diimide-Based Polymer Acceptors}

In addition to their good thermal, chemical, and photochemical stability, rylene diimide-based polymers also exhibit high electron affinity and good electron mobility derived from the electron accepting imide groups, thus making the polymers suitable for use in various electronic fields $[24,39,40]$. In this section, we summarize the rylene diimide-based polymers used as acceptors in OPVs. These include perylene diimide (PDI)-, naphthalene diimide (NDI)-, and dithienocoronene diimide (DTCDI)-based polymer acceptors.

\subsection{PDI-Based Polymer Acceptors}

The electron-withdrawing PDI cores can be substituted in the bay or imide position when copolymerized with various electron-rich units such as dithienothiophene (DTT) and DTP to form electron-accepting polymers [26]. PDI-based polymers substituted in the bay position may exhibit good solubility because of the long branched alkyl chain on the imide N-atom. Imide-substitution results in polymers containing the PDI unit in the backbone or in polymers with pendant PDIs. The photophysical properties and device performance parameters of PDI-based polymer acceptors (1-12) are summarized in Table 1.

Marder and co-workers first developed polymer acceptors having the bay-substituted PDI unit. Good solubility was achieved by introducing long and/or branched alkyl chains onto the imide N-atom. In 2007, they synthesized a new conjugated polymer (PPDI-DTT, 1, Figure 2) with alternating DTT and PDI units that exhibited high electron mobility of $1.3 \times 10^{-2} \mathrm{~cm}^{2} \mathrm{~V}^{-1} \mathrm{~s}^{-1}$, excellent thermal stability (up to $410{ }^{\circ} \mathrm{C}$ ), and high electron affinity, with a LUMO energy level of $-3.9 \mathrm{eV}$. The weight average-molecular weight $\left(M_{\mathrm{w}}\right)$ of $\mathbf{1}$ was 15,000 with a narrow polydispersity index of 1.5 [41]. All-polymer solar cells were fabricated by using polymer acceptor $\mathbf{1}$ and a polymer donor of polythiophene derivative (D2, Figure 3). The BHJ device exhibited an average PCE of 1\% with an open circuit voltage $\left(V_{\mathrm{OC}}\right)$ of $0.63 \mathrm{~V}$, a $J_{\mathrm{SC}}$ of $4.2 \mathrm{~mA} / \mathrm{cm}^{2}$, and a fill factor (FF) of 0.39 under white-light illumination (AM 1.5 solar simulator, $100 \mathrm{~mW} / \mathrm{cm}^{2}$ ). Subsequently, they modified the polymer structures by adding more DTT moieties in the polymer backbones, resulting in the polymer acceptors 2 and 3 (Figure 2) in which the PDI cores were bay substituted with two and three DTT units, respectively [42,43]. The highest PCE was achieved with the polymer acceptor 2 having two DTT units in the polymer repeating unit when using D3 (Figure 3) as a donor, mainly because of the high $J_{\mathrm{SC}}$. The devices were optimized at a blend ratio of 3:1 (D:A, w/w) and exhibited a $V_{\mathrm{OC}}$ of $0.69 \mathrm{~V}$, 
a $J_{\mathrm{SC}}$ of $5.02 \mathrm{~mA} / \mathrm{cm}^{2}$, a FF of 0.43 , and a PCE of $1.48 \%$ under simulated AM 1.5 illumination at $100 \mathrm{~mW} / \mathrm{cm}^{2}$.

Recently, Zheng and co-workers introduced longer alkyl side chain into the polymer acceptor $\mathbf{1}$, resulting in the polymer 4 (Figure 2). They fabricated BHJ solar cells with two different donors based on conjugated side-chain isolated polythiophene derivatives (PT4TV (D4) and PT4TV-C (D5), Figure 3) [44]. Despite the structural similarity of the donors, D4 produced a better PCE of $0.99 \%$ than achieved with D5 (0.57\%). The higher PCE of D4 was mainly attributed to the good FF (above 0.50) which was attributed to the high and balanced hole/electron mobility of the D4:4 blend with rapid transfer of the generated carriers. After adding $10 \%$ of chloronaphthalene as a solvent, the PCE of D4:4 was enhanced from $0.99 \%$ to $1.17 \%$.

More recently, Cheng and co-workers fabricated devices with 1 and PBDTTT-C-T (D6) and showed the highest PCE of $3.45 \%$ using binary additives which is the best PCE achieved with all-polymer solar cells to date [28]. The nonvolatile additive enhanced miscibility of donor and acceptor suppressing aggregation of $\mathbf{1}$, and the other additive, 1,8-diiodooctane, increased aggregation and crystallization of $\mathbf{D 6}$ resulting in suitable phase separation and balanced charge transport.

Hasimoto and coworkers synthesized several PDI-based electron acceptors including various co-monomer units of DTP (PDTP-PDI, 5), carbazole (PC-PDI, 6), vinylene, thiophene, fluorene, and dibenzosilole as replacements for the DTT unit in polymer 1 (Figure 2) [45,46]. Devices were fabricated with various donors of polythiophene derivative D7, DPP-based low band-gap polymer D8 (Figure 3), and D1 for comparison. The device performance varied in the range of $0.11 \%-1.15 \%$ based on the moieties juxtaposed to the perylene unit. For example, the BHJ solar cell fabricated with 5:D7 exhibited a PCE of $0.93 \%$ under AM $1.5\left(100 \mathrm{~mW} / \mathrm{cm}^{2}\right)$ illumination, which was higher than achieved with the 5:D1 cells $(0.17 \%)$. The decreased efficiency obtained with D1 was attributed to the lower $J_{\mathrm{SC}}$ due to the rough surface and coarse phase separation morphology related to the poor miscibility of D1 and the PDI-based acceptors. Among the six acceptors, 6 produced the highest PCE of 1.15\% with donor D7, using chlorobenzene solvent in the active layer. By changing the solvent to toluene/chloroform, the PCE achieved with D7:6 was improved to 2.23\%.

Imide-substituted PDI-based polymers were initially developed by Janssen and co-workers for OPV in 2003 [47]. They synthesized two alternating polymers (7 and 8, Figure 2) consisting of oligo(p-phenylene vinylene) and PDI segments connected via saturated spacers of the flexible unconjugated alkyl or phenyl groups, thus forming a new class of donor-acceptor polymers. Devices with ITO/PEDOT:PSS/7 or 8/LiF/Al configuration exhibited high $V_{\mathrm{OC}}$ values $(1.20 \mathrm{~V}$ and $0.97 \mathrm{~V}$, respectively), whereas the $J_{\mathrm{SC}}$ values were extremely low because of fast geminate recombination.

Later, Sharma and co-workers synthesized the alternating phenylenevinylene and PDI copolymer 9 (Figure 2) via Heck coupling for use as an acceptor in BHJ solar cells [48]. Copolymer 9 exhibited broad absorption extending up to about $800 \mathrm{~nm}$ with a maximum peak at $c a .500 \mathrm{~nm}$ and an optical band gap of $1.66 \mathrm{eV}$. The solubility of $\mathbf{9}$ increased upon the introduction of tert-butyl and hexyloxy side groups with respective glass transition $\left(T_{\mathrm{g}}\right)$ and decomposition temperatures $\left(T_{\mathrm{d}}\right)$ of 72 and $370^{\circ} \mathrm{C}$. A PCE of $1.67 \%$ was obtained by blending acceptor $\mathbf{9}$ and a poly(3-phenyl hydrazone thiophene) (PPHT, D9, Figure 3) donor. After annealing, the enhanced PCE (2.32\%) was evidenced by an increase in the efficiency of separation of the exciton; this PCE is one of the highest reported values achieved with imide-substituted PDI-based polymer acceptors. 
Table 1. Perylene diimide (PDI)-based polymer acceptors ${ }^{\mathrm{a}}$.

\begin{tabular}{|c|c|c|c|c|c|c|c|c|}
\hline \multicolumn{2}{|c|}{ Acceptor [Ref] } & $\begin{array}{l}M_{\mathrm{n}} \\
M_{\mathrm{w}}\end{array}$ & $\begin{array}{l}\text { Mobility, } \boldsymbol{\mu}_{\mathrm{e}} \\
{\left[\mathrm{cm}^{2} \mathrm{~V}^{-1} \mathrm{~s}^{-1}\right]}\end{array}$ & $\begin{array}{c}\text { HOMO/LUMO } \\
\left(\boldsymbol{E}_{\mathrm{g}}[\mathrm{eV}]\right)\end{array}$ & $\begin{array}{l}V_{\text {OC }} \\
{[V]}\end{array}$ & $\begin{array}{c}\boldsymbol{J}_{\mathbf{S C}} \\
{\left[\mathrm{mA} / \mathrm{cm}^{2}\right]}\end{array}$ & FF & $\begin{array}{c}\text { PCE } \\
{[\%]}\end{array}$ \\
\hline \multirow{4}{*}{1} & \multirow{2}{*}{ [41] } & 10,000 & \multirow{2}{*}{$1.3 \times 10^{-2 b}$} & \multirow{2}{*}{$\begin{array}{c}-5.9 /-3.9 \\
(2.0)\end{array}$} & 0.63 & 4.2 & 0.39 & 1 \\
\hline & & 15,000 & & & \multicolumn{4}{|c|}{ (ITO/PEDOT:PSS/D2:1(1:1)/Al) } \\
\hline & \multirow{2}{*}[28]{} & \multirow{2}{*}{-} & \multirow{2}{*}{$3.37 \times 10^{-5 c}$} & \multirow{2}{*}{$\begin{array}{c}-5.9 /-3.9 \\
(2.0)\end{array}$} & 0.75 & 8.55 & 0.52 & 3.45 \\
\hline & & & & & \multicolumn{4}{|c|}{ (ITO/PEDOT:PSS/D6:1(1:1)/Ca/Al) } \\
\hline \multirow{2}{*}{2} & \multirow{2}{*}[42]{} & 20,000 & \multirow{2}{*}{-} & \multirow{2}{*}{$\begin{array}{c}-5.7 /-3.8 \\
(1.9)\end{array}$} & 0.69 & 5.02 & 0.43 & 1.48 \\
\hline & & 43,000 & & & \multicolumn{4}{|c|}{ (ITO/PEDOT:PSS/D3:2(3:1)/Ca/Al) } \\
\hline \multirow{2}{*}{3} & \multirow{2}{*}{ [43] } & 15,000 & \multirow{2}{*}{-} & \multirow{2}{*}{$\begin{array}{c}-5.4 /-4.0 \\
(1.4)\end{array}$} & 0.69 & 2.80 & 0.40 & 0.77 \\
\hline & & 27,000 & & & \multicolumn{4}{|c|}{ (ITO/PEDOT:PSS/D3:3(1:1)/Ca/Al) } \\
\hline \multirow{4}{*}{4} & \multirow{4}{*}[44]{} & 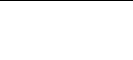 & \multirow{4}{*}{-} & \multirow{4}{*}{$\begin{array}{c}-5.7 /-3.8 \\
(1.9)\end{array}$} & 0.67 & 3.24 & 0.51 & 1.17 \\
\hline & & - & & & \multicolumn{4}{|c|}{ (ITO/PEDOT:PSS/D4:4(2:1)/Ca/Al) } \\
\hline & & & & & 0.75 & 1.60 & 0.45 & 0.57 \\
\hline & & & & & \multicolumn{4}{|c|}{ (ITO/PEDOT:PSS/D5:4(3:1)/Ca/Al) } \\
\hline \multirow{6}{*}{5} & \multirow{4}{*}[45]{} & 6,300 & 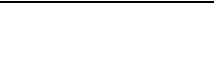 & $-5.49 /-3.83$ & 0.66 & 3.05 & 0.46 & 0.93 \\
\hline & & 8,500 & - & (1.66) & (IT & DOT:PSS & $5(2: 1)$ & \\
\hline & & & & & 0.42 & 1.86 & 0.53 & 0.41 \\
\hline & & & & & (IT & DOT:PSS & $5(1: 1)$ & \\
\hline & {$[1 C]$} & 6,300 & $4-4 \mathrm{~b}$ & $-5.49 /-3.83$ & 0.46 & 0.76 & 0.50 & 0.17 \\
\hline & {$[40]$} & 8,500 & $2.3 \times 10$ & (1.67) & (IT & DOT:PSS & $5(2: 1)$ & \\
\hline 6 & {$[46]$} & 12,100 & $17 \times 10^{-4 b}$ & $-5.83 /-3.66$ & 0.70 & 6.35 & 0.50 & 2.23 \\
\hline 0 & {$[40]$} & 19,600 & $1.7 \times 10$ & $(2.17)$ & (IT & DOT:PSS & $6(2: 1)$ & \\
\hline & & & & & 0.58 & 0.91 & 0.55 & 0.29 \\
\hline & & & & & (IT & DOT:PSS & $6(2: 1)$ & \\
\hline $\mathbf{0}$ & {$[48]$} & 7,800 & $85 \times 10^{-3 c}$ & $-5.75 /-3.95$ & 0.6 & 2.98 & 0.39 & 2.32 \\
\hline 9 & [48] & 19,000 & $8.5 \times 10$ & (1.76) & & ITO/D9:9 & $/ / \mathrm{Al})^{e}$ & \\
\hline 10 & [49] & 6,000 & $5 \times 10^{-4 d}$ & - & 0.33 & 0.60 & 0.46 & 0.1 \\
\hline 10 & [4Y] & - & $5 \times 10$ & - & & EDOT:PS & $1: 10(2$ & \\
\hline 11 & [35] & 13,600 & - & - & 0.51 & 2.57 & 0.37 & 0.49 \\
\hline II & [35] & - & - & - & & /PEDOT: & 11/Lif & \\
\hline 12 & {$[36]$} & 29,500 & 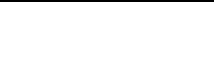 & - & 0.44 & 1.5 & 0.25 & 0.2 \\
\hline 12 & [30] & 33,900 & - & (1.93) & & /PEDOT:I & 12/LiF & \\
\hline
\end{tabular}

Notes: ${ }^{\text {a }}$ Measured at AM 1.5G 100mW/cm² unless indicated; By ${ }^{\mathrm{b}}$ OFET, ${ }^{\mathrm{c}}$ space charge limited current (SCLC), and ${ }^{\mathrm{d}}$ the time-of-flight (TOF) measurements; ${ }^{\mathrm{e}}$ Measured at $30 \mathrm{~mW} / \mathrm{cm}^{2}$ 
Figure 2. Molecular structures of perylene diimide (PDI)-based polymer acceptors (1-12).
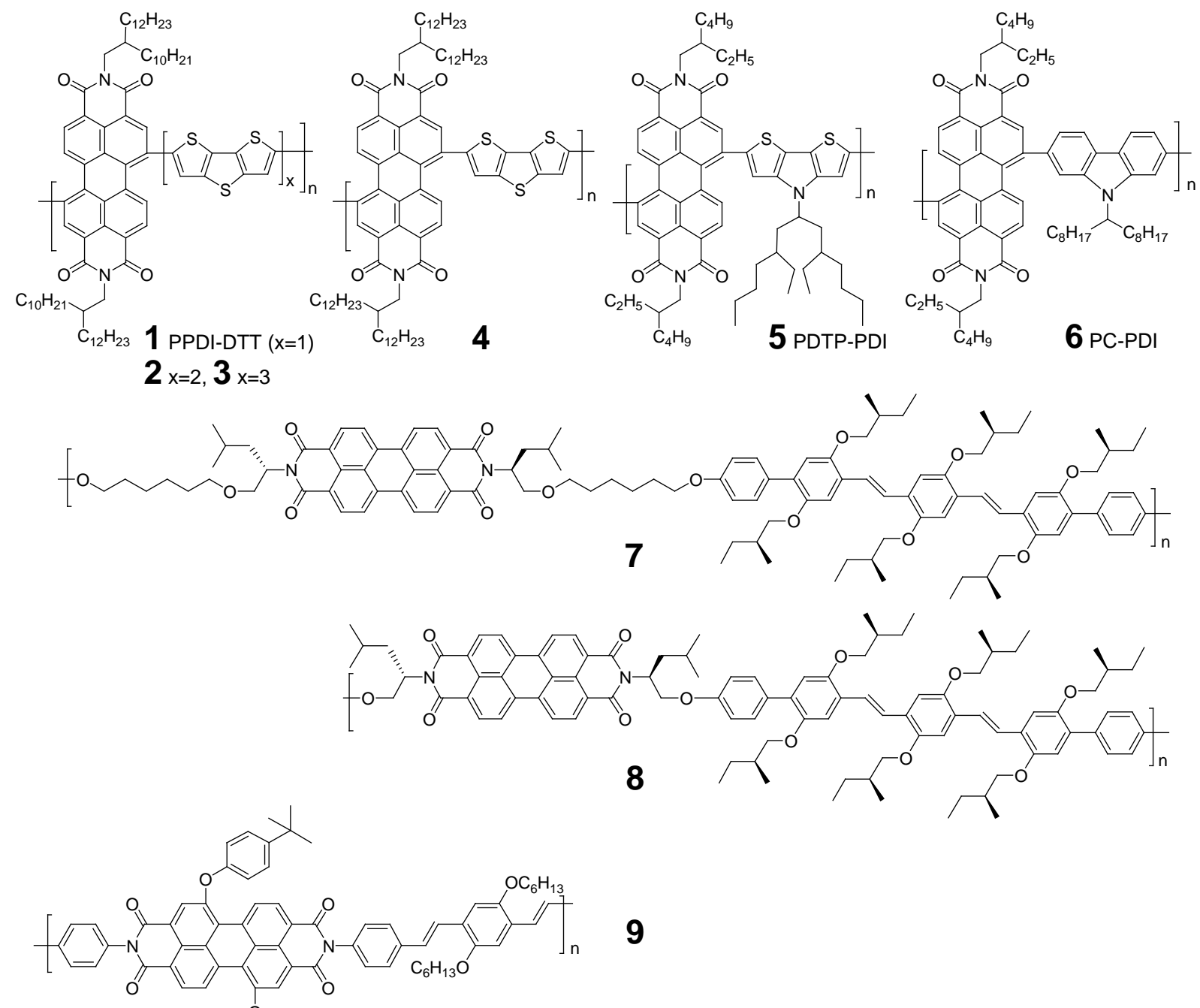

\section{9}

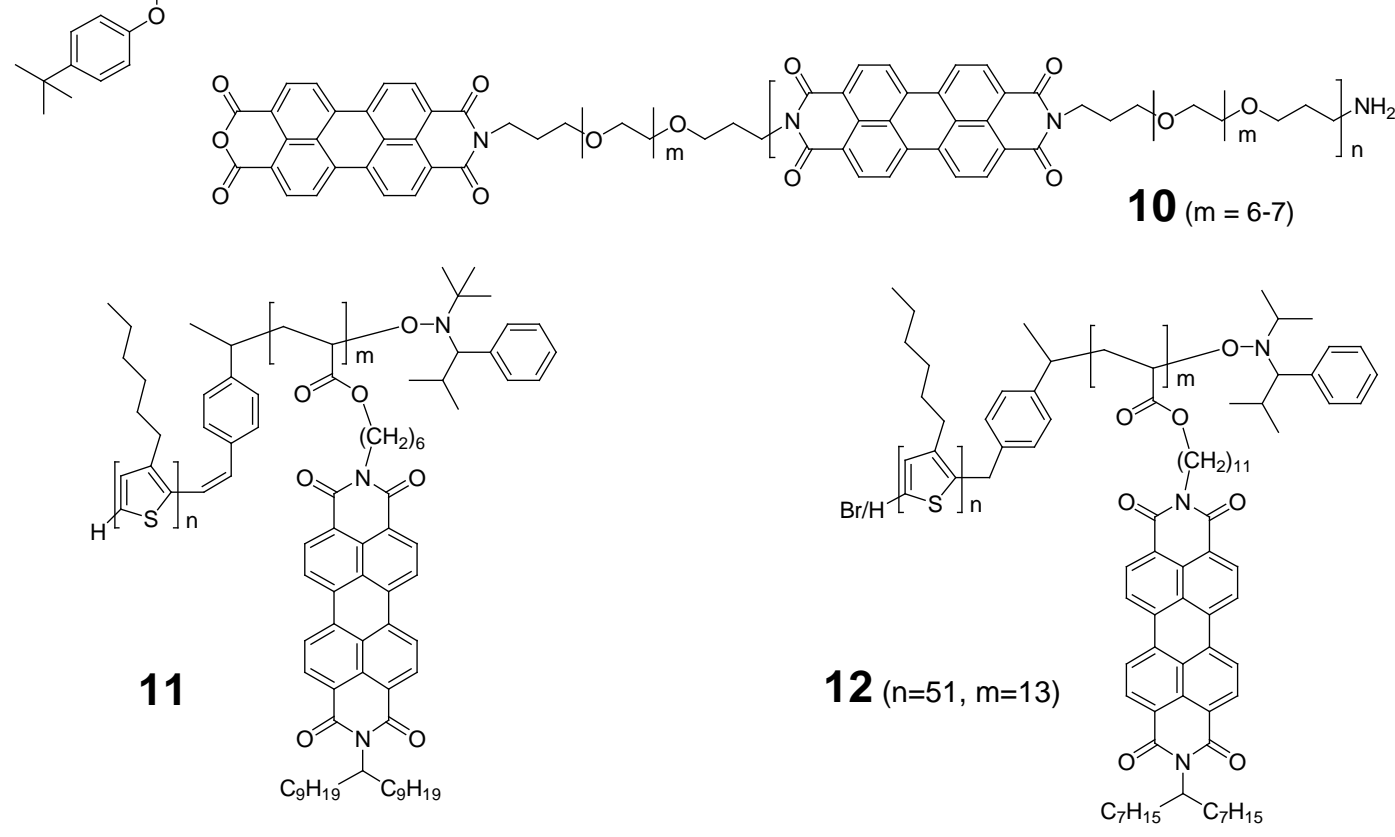


Figure 3. Molecular structures of polymer donors (D2-D9).

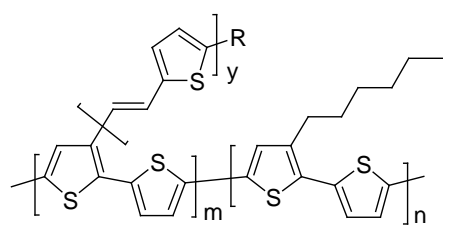

D2 $y=2, R=n-\mathrm{C}_{12} \mathrm{H}_{25}, \mathrm{~m}: \mathrm{n}=0.6: 1$

D3 $y=3, R=n-C_{4} H_{9}, m: n=0.4: 1$

D7 $y=3, R=n-C_{6} H_{13}, m: n=0.25: 1$

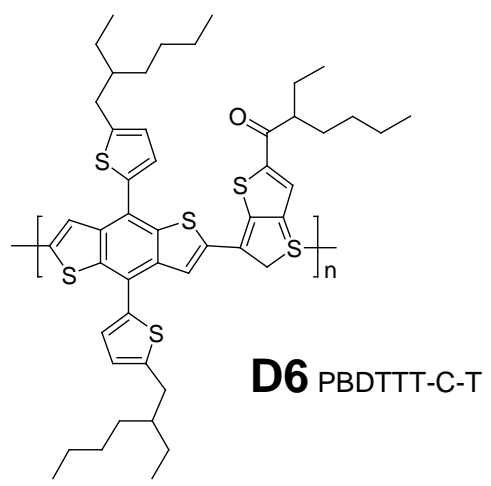

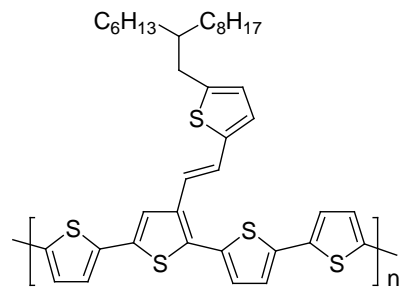

D4 PT4TV

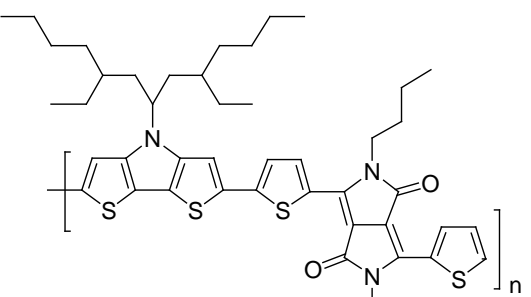

D8

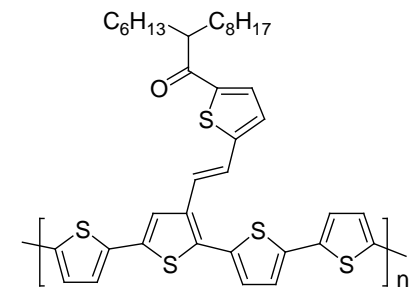

D5 PT4TV-C

In 2011, Liang also reported an imide-substituted PDI-based polymer 10 (Figure 2) having a poly(ethylene glycol) spacer [49]. The flexible spacer resulted in increased solubility, promoting $\pi-\pi$ interactions between the perylene cores. However, a low PCE of $0.1 \%$ was obtained because of the large-scale phase-separation of $\mathbf{1 0}$ and $\mathbf{D} 1$ with a $V_{\mathrm{OC}}$ of $0.33 \mathrm{~V}$, a $J_{\mathrm{SC}}$ of $0.6 \mathrm{~mA} / \mathrm{cm}^{2}$, and a FF of 0.46 .

Another approach in the development of imide-substituted PDI-based polymers involves the attachment of PDI to a polymeric scaffold. Zhang and Sommer reported achieving PCEs of $0.49 \%$ and $0.20 \%$ with acceptors $\mathbf{1 1}$ and 12, respectively, in single component devices using the BCPs containing PDI moieties as side chains (Figure 2) [35,36].

\subsection{NDI-Based Polymer Acceptors}

In the initial studies, NDI-based small molecules were reported to show relatively poor features as acceptors in OPVs compared to the PDI-based counterparts, attributed to the small fused-ring unit, large band-gap, and minor absorption of the former in the visible region [24]. In later studies, polymerization of NDI units was employed to increase the conjugation length and enhance the PCE [40]. The photophysical properties and device performance parameters of NDI-based polymer acceptors (13-24) are summarized in Table 2.

The first NDI-based polymer was a ladder-type poly(benzimidazobenzophenanthroline ladder) (BBL, 13, Figure 4) synthesized via a one-step condensation of naphthalene tetracarboxylic acid and tetra-aminobenzene in polyphosphoric acid by Jenekhe et al [14]. The spin-coated bi-layer BHJ cells were fabricated with a poly(phenylenevinylene) (PPV, D10, Figure 5) donor using the ITO/D10/13/Al device configuration. The estimated PCE value of $0.7 \%$ was obtained using $10 \mathrm{~mW} / \mathrm{cm}^{2}$ illumination. After annealing at $100^{\circ} \mathrm{C}$, the PCE increased up to $1.5 \%$ [50]. 
Table 2. Naphthalene diimide (NDI)- and dithienocoronene diimide (DTCDI)-based polymer acceptors ${ }^{a}$.

\begin{tabular}{|c|c|c|c|c|c|c|c|c|}
\hline \multicolumn{2}{|c|}{ Acceptor [Ref] } & $\begin{array}{l}M_{\mathrm{n}} \\
M_{\mathrm{w}}\end{array}$ & $\begin{array}{l}\text { Mobility, } \boldsymbol{\mu}_{\mathbf{e}} \\
{\left[\mathrm{cm}^{2} \mathrm{~V}^{-1} \mathrm{~s}^{-1}\right]^{\mathrm{b}}}\end{array}$ & $\begin{array}{c}\text { HOMO/LUMO } \\
\left(\boldsymbol{E}_{\mathrm{g}}[\mathrm{eV}]\right)\end{array}$ & $\begin{array}{l}V_{\mathbf{O C}} \\
{[\mathrm{V}]}\end{array}$ & $\begin{array}{c}\boldsymbol{J}_{\mathbf{S C}} \\
{\left[\mathrm{mA} / \mathrm{cm}^{2}\right]}\end{array}$ & FF & $\begin{array}{l}\text { PCE } \\
{[\%]}\end{array}$ \\
\hline \multirow{4}{*}{13} & \multirow{2}{*}{ [14] } & \multirow{2}{*}{-} & & \multirow{2}{*}{-} & 1.2 & 1.2 & 0.43 & 0.7 \\
\hline & & & & & \multicolumn{4}{|c|}{ (ITO/D10(50nm)/13(50nm)/Al) } \\
\hline & \multirow{2}{*}[50]{} & \multirow{2}{*}{-} & \multirow{2}{*}{-} & \multirow{2}{*}{-} & 1.10 & 2.15 & 0.50 & 1.5 \\
\hline & & & & & \multicolumn{4}{|c|}{$(\mathrm{ITO} / \mathbf{D 1 0}(60 \mathrm{~nm}) / \mathbf{1 3}(60 \mathrm{~nm}) / \mathrm{Al})^{\mathrm{c}}$} \\
\hline \multirow{6}{*}{14} & \multirow{2}{*}[51]{} & 50,000 & \multirow{2}{*}{$\sim 5 \times 10^{-3}$} & \multirow{2}{*}{$\begin{array}{c}-5.6 /-4.0 \\
(1.6)\end{array}$} & 0.48 & 2.39 & 0.54 & 0.62 \\
\hline & & 250,000 & & & \multicolumn{4}{|c|}{ (ITO/PEDOT:PSS/D1:14(1:2)/LiF/Al) } \\
\hline & \multirow{2}{*}[52]{} & \multirow{2}{*}{-} & \multirow{2}{*}{0.8} & \multirow{2}{*}{$\begin{array}{c}-5.45 /-4 \\
(1.45)\end{array}$} & 0.52 & 1.41 & 0.29 & 0.21 \\
\hline & & & & & \multicolumn{4}{|c|}{ (ITO/PEDOT:PSS/D1:14(1:1)/Al) } \\
\hline & \multirow{2}{*}[53]{} & 26,200 & \multirow{2}{*}{0.85} & \multirow{2}{*}{$\begin{array}{c}-5.8 /-4.35 \\
(1.45)\end{array}$} & 0.56 & 3.77 & 0.65 & 1.4 \\
\hline & & 85,200 & & & \multicolumn{4}{|c|}{ (ITO/PEDOT:PSS/D1:14(4:3)/Sm/Al) } \\
\hline \multirow{2}{*}{15} & \multirow{2}{*}{ [53] } & 36,600 & 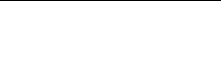 & $-5.35 /-4.15$ & 0.63 & 2.43 & 0.70 & 1.1 \\
\hline & & 59,300 & - & $(1.2)$ & (ITO/ & DOT:PSS/I & $14(4: 3)$ & $\mathrm{a} / \mathrm{Al})$ \\
\hline 16 & {$[541]$} & 22,200 & ( 07 & $-5.95 /-4.55$ & 0.53 & 3.79 & 0.44 & 0.9 \\
\hline 10 & {$[34]$} & 40,300 & 0.07 & (1.4) & (ITO/ & DOT:PSS/L & 16(1:3) & F/Al) \\
\hline 17 & {$[55]$} & 23,900 & $2 \times 10^{-4}$ & $-5.77 /-4.0$ & 0.61 & 3.80 & 0.56 & 1.30 \\
\hline 17 & ] [כ] & 31,500 & $2 \times 10$ & (1.77) & (ITC & nO/D11:17 & 1)/Mol & \\
\hline 18 & {$[55]$} & 26,100 & $2 \times 10^{-3}$ & $-5.70 /-4.0$ & 0.75 & 6.53 & 0.60 & 2.96 \\
\hline 10 & ] & 31,600 & & $(1.70)$ & (ITC & nO/D11:18 & 1)/Mo( & Ag) \\
\hline 19 & {$[55]$} & 79,000 & $7 \times 10^{-3}$ & $-5.65 /-4.0$ & 0.76 & 7.78 & 0.55 & 3.26 \\
\hline & & 177,900 & $7 \times 10$ & (1.65) & (ITC & nO/D11:19 & ) $/ \mathrm{Mo}$ & Ag) \\
\hline 20 & [37] & 26,000 & 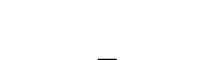 & $-5.60 /-4.22$ & 0.56 & 4.57 & 0.50 & 1.28 \\
\hline 20 & {$[0 /]$} & 41,600 & - & (1.38) & (ITO/ & DOT:PSS/I & $20(1: 1$ & /Al) \\
\hline 21 & {$[56]$} & 62,500 & $70 \times 10^{-3}$ & $-5.45 /-3.88$ & 0.51 & 0.46 & 0.39 & 0.11 \\
\hline 21 & {$[00]$} & 206,300 & & (1.57) & (ITC & EDOT:PSS & 1:21(1 & Al) \\
\hline 22 & {$[56]$} & 21,300 & $48 \times 10^{-3}$ & $-5.31 /-3.91$ & 0.48 & 0.19 & 0.48 & 0.045 \\
\hline & & 61,800 & $4.8 \times 10$ & $(1.40)$ & (ITC & EDOT:PSS & 1:22(1 & $\mathrm{Al})$ \\
\hline 23 & {$[56]$} & 92,400 & $12 \times 10^{-2}$ & $-5.29 /-3.92$ & 0.47 & 0.57 & 0.55 & 0.13 \\
\hline 23 & {$[50]$} & 332,600 & $1.2 \times 10$ & (1.37) & (ITC & EDOT:PSS & 1:23(1 & $\mathrm{Al})$ \\
\hline 24 & {$[57]$} & 18,700 & $215 \times 10^{-6}$ & $-5.98 /-3.77$ & 0.82 & 1.09 & 0.36 & 0.32 \\
\hline 24 & {$[0 /]$} & 33,600 & & $(2.21)$ & (ITC & EDOT:PSS & 1:24(1 & Al) \\
\hline 25 & Г201 & 9,800 & 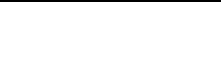 & $-5.70 /-3.51$ & 0.92 & 2.14 & 0.43 & 0.84 \\
\hline 25 & [39] & 16,500 & - & (2.19) & (ITO/ & DOT:PSS/I & $25(1:$ & $\mathrm{Sa} / \mathrm{Al})$ \\
\hline
\end{tabular}

Notes: ${ }^{\mathrm{a}}$ Measured at AM $1.5 \mathrm{G} 100 \mathrm{~mW} / \mathrm{cm}^{2}$ unless indicated; ${ }^{\mathrm{b}}$ By OFET measurement; ${ }^{\mathrm{c}}$ Measured at $80 \mathrm{~mW} / \mathrm{cm}^{2}$ 
Figure 4. Molecular structures of naphthalene diimide (NDI)-based polymer acceptors (13-25).

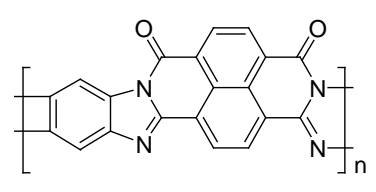

13 BBL

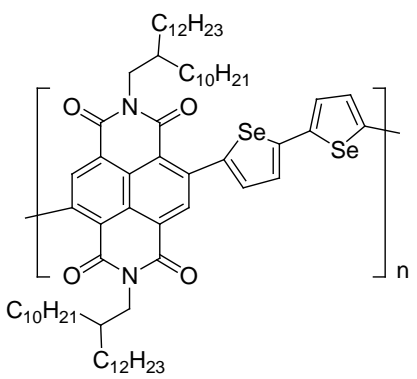

16 PNDIBS

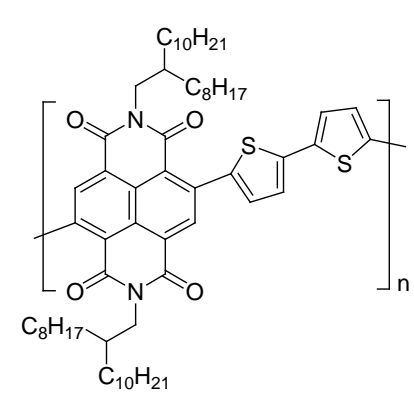

14 P(NDI2OD-T2)

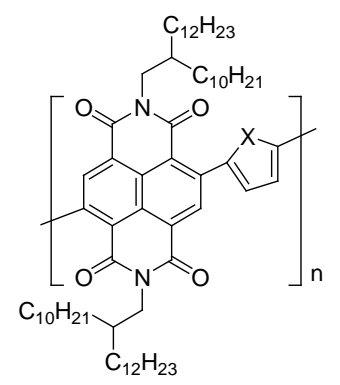

17 PNDIT $(x=\mathrm{s})$

18 PNDIS $(x=S e)$

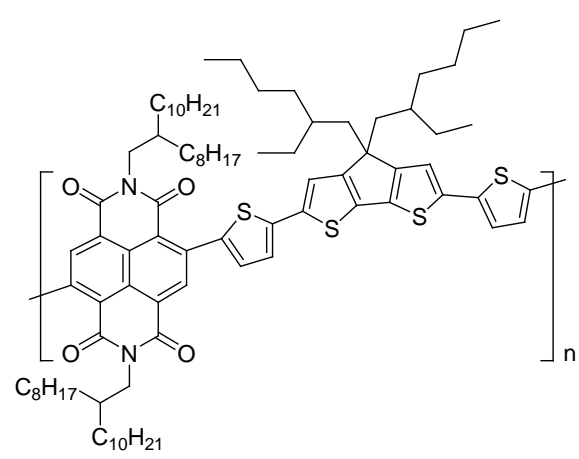

15 P(NDI-TCPDTT)

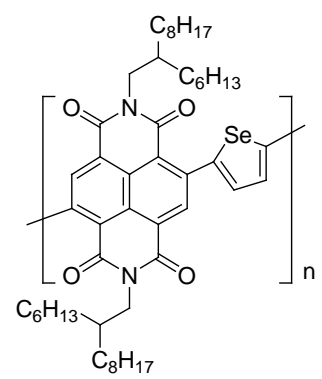

19 PNDIS-HD

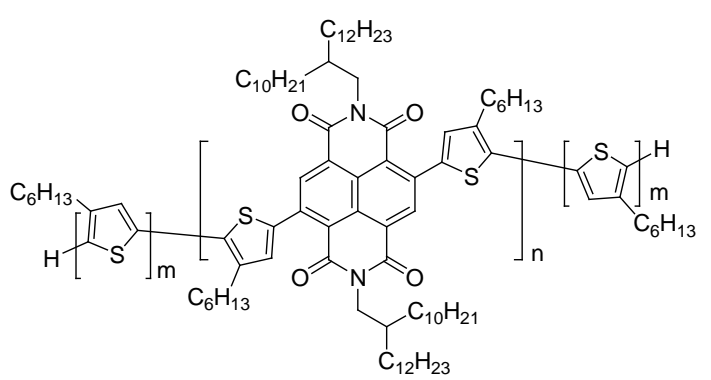

20 P3НT-PNBI-P3HT

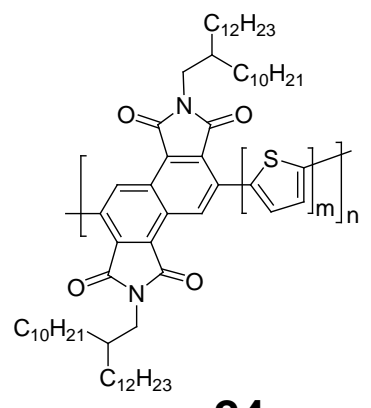

$24(m=1-3)$

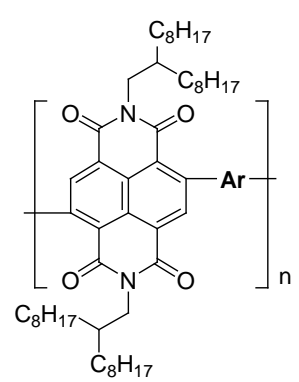

$A r=-\left\|s^{s}\right\|$

21 PNDI-2fTH
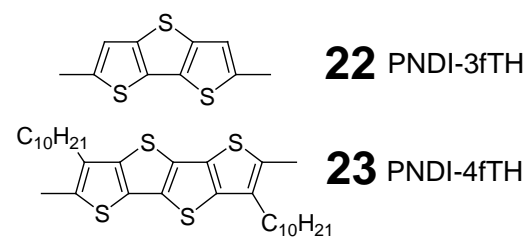

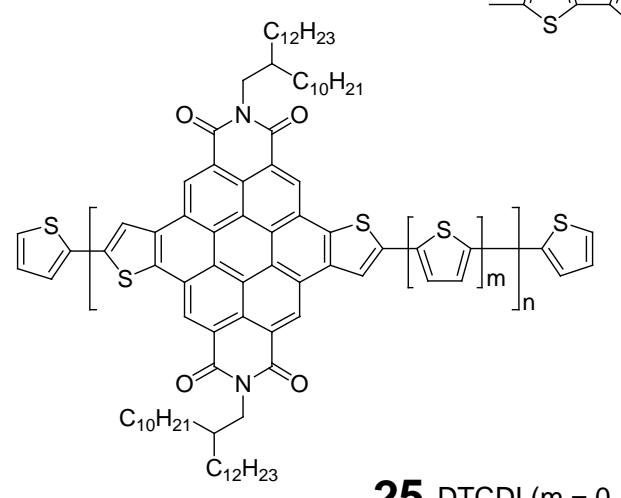

25 DTCDI $(m=0-2)$ 
Figure 5. Molecular structures of polymer donors (D10-D12).

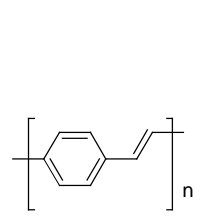

D10 PPV

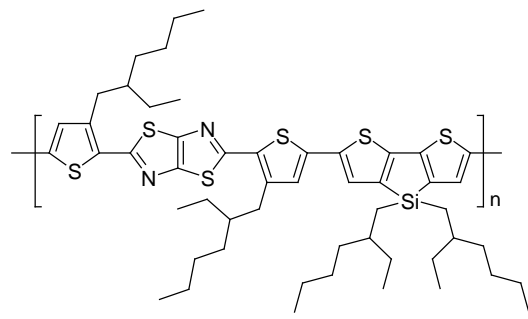

D11 PSEHTT

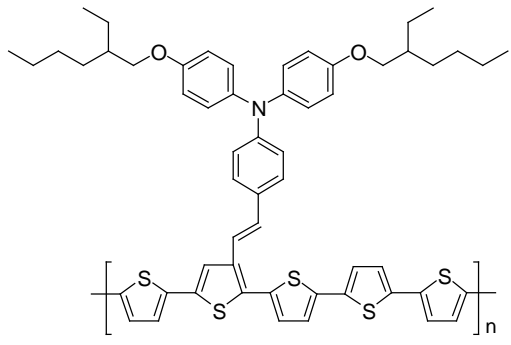

D12 PT5TPA

In 2011, Loi and co-workers presented all-polymer BHJ solar cells composed of the NDI-based polymer acceptor, P(NDI2OD-T2) (14, Figure 4) and a polymer donor, D1. A PCE of 0.16\% was achieved using chlorobenzene and $o$-dichlorobenzene [51]. Polymer $\mathbf{1 4}$ was synthesized via the Stille coupling reaction between $N, N^{\prime}$-dialkyl-2,6-dibromonaphthalene-1,4,5,8-bis(dicarboximide) and 5,5'-bis(trimethylstannyl)-2,2'-dithiophene. The narrow band-gap of $\mathbf{1 4}$ (ca. $1.6 \mathrm{eV}$ ) resulted in UV absorption up to $850 \mathrm{~nm}$, thus the absorption was complementary to the visible spectral range in the case of the blend film. A FF value of 0.67 was obtained for these devices, suggesting compatible charge transfer and free carrier generation in the interface of the D1:14 blend. Despite the excellent charge transport, the devices employing chlorobenzene or $o$-dichlorobenzene as a solvent exhibited low $J_{\mathrm{SC}}$ values. Blending the donor and acceptor using xylene as a solvent resulted in a PCE of $0.62 \%$ that was attributed to improved phase separation of D1:14, resulting in a two-fold increase of the $J_{\mathrm{SC}}$. Sirringhaus and co-workers also used 14 as an electron acceptor [52]. Despite the high electron mobility $\left(0.8 \mathrm{~cm}^{2} \mathrm{~V}^{-1} \mathrm{~s}^{-1}\right)$, near-infrared absorption band, and compatible energy levels of 14 , the PCE of BHJ solar cells fabricated with 14 and D1 using chloroform as a solvent was only $0.21 \%$. This low efficiency was explained in terms of the coarse phase separation of the D1:14 blends with domains in the range of 0.2 to 1 micrometer and the rapid, initial geminate recombination of the charge population within 200 ps of excitation. In 2012, an improved PCE of 1.4\% was reported by Neher et al. using the same donor and acceptor materials by changing the solvent to $p$-xylene and chloronaphthalene [53]. The enhanced PCE was mainly attributed to the large increase of the $J_{\mathrm{SC}}$ with the use of a proper solvent ( $p$-xylene:chloronaphthalene $=50: 50)$. They also synthesized another NDI-based polymer acceptor, P(NDI-TCPDTT) (15, Figure 4), having an additional CPDT moiety. A PCE of 1.1\% and a FF of up to 0.70 were obtained in D1:15 cells using tetralin as a solvent, which produced a higher $J_{\mathrm{SC}}$ than other solvents such as chloroform, $p$-xylene, and a blend of $p$-xylene and chloronaphthalene.

Jenekhe et al. introduced selenophene into polymer 14 instead of thiophene as a structural modification. The newly synthesized crystalline copolymer acceptor (PNDIBS, 16, Figure 4) exhibited high electron mobility $\left(0.07 \mathrm{~cm}^{2} \mathrm{~V}^{-1} \mathrm{~s}^{-1}\right)$ and a broad visible-near infrared absorption band with an optical band gap of $1.4 \mathrm{eV}$ [54]. All-polymer BHJ solar cells comprised of $\mathbf{1 6}$ as an acceptor and D1 as a donor showed a PCE of 0.9\%. Later, they also developed three other acceptors; PNDIT (17), PNDIS (18), and PNDIS-HD (19, Figure 4) which have one thiophene or selenophene next to the NDI unit in the repeating unit [55]. The three acceptors were blended with a thiazolothiazole copolymer donor (PSEHTT, D11, Figure 5). The NDI-thiophene-based polymer 17 produced a lower PCE (1.3\%) than 
the NDI-selenophene-based congeners, 18 (2.96\%) and 19 (3.26\%). The high PCE of 19 was explained in terms of the lamellar crystalline morphology, which makes it a good alternative to $\mathrm{PC}_{60} \mathrm{BM}$.

Nakabayashi and co-workers reported the fully conjugated D-A BCPs composed of poly(naphthalene bisimide) (PNBI)-based electron-accepting and regioregular P3HT-based electron-donating segments P3HT-PNBI-P3HT (20, Figure 4) [37]. The BCPs were synthesized using quasi-living Grignard metathesis polymerization and the Yamamoto coupling reaction and had molecular weights in the range of 21,800-26,000. The polymer acceptors showed a broad absorption in the range of 350-850 nm and had an optical band gap of $1.46 \mathrm{eV}$. Furthermore, thermal annealing extended the light absorption band to $893 \mathrm{~nm}$, which helped to decrease the optical band gap to $1.38 \mathrm{eV}$. The D1:20 device achieved a PCE of $1.28 \%$ with a $V_{\mathrm{OC}}$ of $0.56 \mathrm{~V}$, a $J_{\mathrm{SC}}$ of $4.57 \mathrm{~mA} / \mathrm{cm}^{2}$, and a FF of 0.50 . The absorption of a blend film with a 1:1 (D:A, w/w) blend ratio also exhibited broad absorption up to $950 \mathrm{~nm}$.

Luscombe and co-workers copolymerized fused thiophenes (as electron-rich co-monomer units) with electron-withdrawing NDIs. The copolymers differed in terms of the number of thiophene rings in the fused thiophene systems, resulting in PNDI-2fTh (21), PNDI-3fTh (22), and PNDI-4fTh (23, Figure 4) [56]. The device fabricated with D1:23 showed the highest PCE of 0.13\%, which was associated with the highest $J_{\mathrm{SC}}\left(0.57 \mathrm{~mA} / \mathrm{cm}^{2}\right)$ and FF $(0.55)$ among the evaluated polymers. The values of the charge mobility were enhanced by increasing the number of fused thiophene moieties within the NDI-copolymers, resulting in the increased $J_{\mathrm{SC}}$.

Recently, Zheng et al. designed three angular-shaped naphthalene tetracarboxylic diimide polymers 24 ( $m=1-3$, Figure 4) as acceptors using the Stille coupling reactions [57]. The best PCE of up to $0.32 \%$ was achieved with polymer $\mathbf{2 4}(m=1)$ and $\mathbf{D 1}$ donor in BHJ solar cells. The angular-shaped NDI-containing polymers were characterized by a higher $V_{\mathrm{OC}}$ (up to $0.94 \mathrm{~V}$ ) than the linear-shaped NDI-containing polymers $(<0.6 \mathrm{~V})$ because of the relatively high-lying LUMO levels.

\subsection{DTCDI-Based Polymer Acceptors}

Recently, Zhan and co-workers introduced three conjugated polymer acceptors (25, Figure 4) based on DTCDI with thiophene numbers ranging from 0-2 [39]. The size of the 25 core is larger than that of the PDI core, and the coplanar backbone of $\mathbf{2 5}$ with negligible dihedral angles may result in enhanced intermolecular $\pi-\pi$ interactions. The polymers exhibited good thermal stability and broad absorption spectra ranging from 400-700 $\mathrm{nm}$. The maximum absorption peak was red-shifted and the optical band-gap decreased with increasing numbers of thiophene units in the polymer. An upward shift of the HOMOs with increasing numbers of thiophene units resulted in a decrease of the optical band-gap, whereas the LUMOs were insensitive to the number of thiophene units. The BHJ solar cells fabricated with the polythiophene derivative donor of PT5TPA (D12, Figure 5) achieved a PCE of $0.31-0.84 \%$. The photophysical properties and device performance parameters of DTCDI-based polymer acceptors (25) are summarized in Table 2.

\section{Fluorene and BT-Based Polymer Acceptors}

The fluorene and BT-based polymers are known as luminescent $n$-type polymers having high electron affinity due to the strong electron-withdrawing BT unit [58]. Arias and Mackenzie et al. first 
reported photovoltaic properties derived from polyfluorenes [59]. They used poly(9,9'-dioctylfluoreneco-benzothiadiazole) (F8BT, 26, Figure 6) (also known as P8BT and PF8BT), which has an electron affinity of $3.53 \mathrm{eV}$, as an acceptor, and a triarylamine-based hole-transporting polymer, poly(9,9'-dioctylfluorene-co-bis- $N, N^{\prime}$-(4-butylphenyl)-bis- $N, N^{\prime}$-phenyl-1,4-phenylenediamine) (PFB, D13, Figure 6) as a donor in photovoltaic devices employing a 1:1 (D:A, w/w) blend ratio. Respective devices fabricated by spin-coating with chloroform or xylene had external quantum efficiency (EQE) values of $4 \%$ and $1.8 \%$. Friend et al. also reported the charge generation kinetics and transport mechanisms of blended films with D13 and 26 with various blend ratios [60]. Kim and Bradley et al. fabricated devices with blends of a D1 donor and a $\mathbf{2 6}$ acceptor [61]. The PCEs of the resultant devices were enhanced from $0.02-0.13 \%$ after inserting a LiF layer, but the PCE was still low because of the low electron mobility of $\mathbf{2 6}$.

Figure 6. Molecular structures of fluorene and benzothiadiazole (BT)-based polymer acceptors (26-29) together with polymer donor (D13).

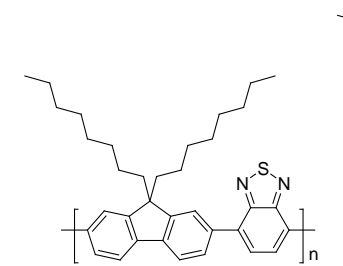

26 F8BT
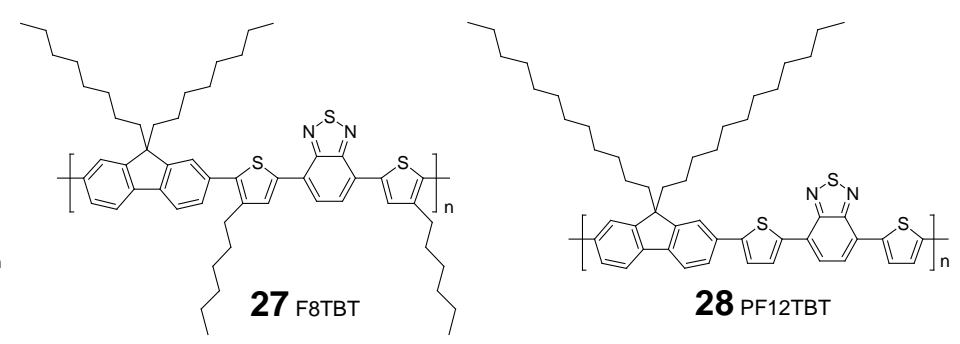

28 PF12TBT
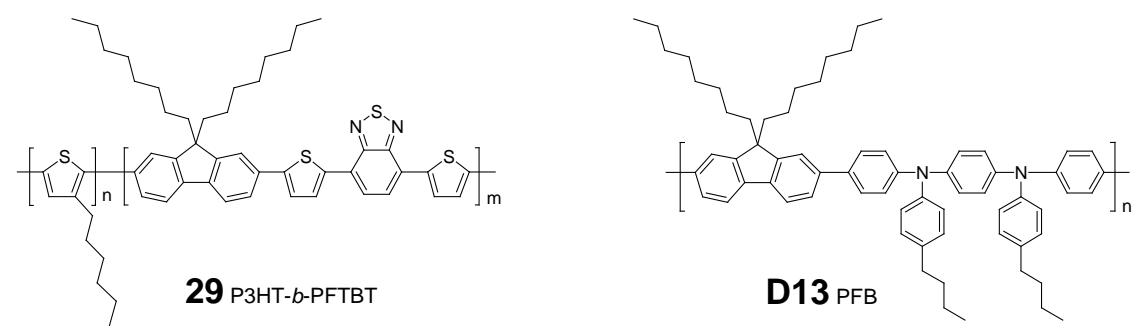

McNeill et al. fabricated BHJ solar cells by employing F8TBT (27, Figure 6) as an electron acceptor with a D1 donor [62]. The polymer 27 contains thiophene groups next to the BT unit, compared to 26, and a PCE of 1.8\% was obtained with the optimized D1:27 device with a LiF layer. They also investigated the effect of annealing on the D1:27 BHJ solar cells $[63,64]$. The PCE was enhanced from $0.14 \%-1.20 \%$ by annealing of the completed devices, and the enhancement of the hole mobility after annealing was attributed to increased molecular ordering of the polymers and the red-shifted optical absorption of the blend films. Furthermore, in 2010, Friend and Huck et al. fabricated D1/27 devices using a double nano-imprinting process, achieving a PCE of 1.85\% [65].

Ito et al. fabricated all-polymer BHJ solar cells consisting of a D1 donor and a PF12TBT (28, Figure 6) acceptor that possesses longer alkyl side chains in the fluorene unit compared to 27 [66]. The PCE was strongly dependent on the solvent. The higher PCE of 2.0\% was achieved in the blend using chloroform, higher than achieved using chlorobenzene or o-dichlorobenzene. Nanoscale-phaseseparated domains were observed, which accounts for the highly efficient performance of the devices. In addition, they synthesized polymer 28 with different $M_{\mathrm{w}}$ of 8500, 20,000, and 78,000 [67]. The 
highest PCE of $2.7 \%$ and a FF value of up to 0.55 was achieved with the high-molecular-weight 28 and a D1 donor in BHJ solar cells because of the enhanced electron and hole transport.

Recently, Verduzco and co-workers reported a remarkable PCE of 3.1\% in single-component devices using the fully conjugated BCP P3HT-b-PFTBT (29, Figure 6) that self-assembled into meso-scale lamellar morphologies [38]. This high PCE is even higher than that of the device fabricated with D1 and 27 as donor and acceptor, respectively. The use of the BCP produced well-controlled $\mathrm{D}-\mathrm{A}$ interfaces which resulted in the best performance of BHJ solar cells among the devices employing fluorene and BT-based $n$-type polymers.

The photophysical properties and device performance parameters of fluorene and BT-based polymers (26-29) are summarized in Table 3.

Table 3. Fluorene and benzothiadiazole (BT)-based polymer acceptors ${ }^{\text {a }}$.

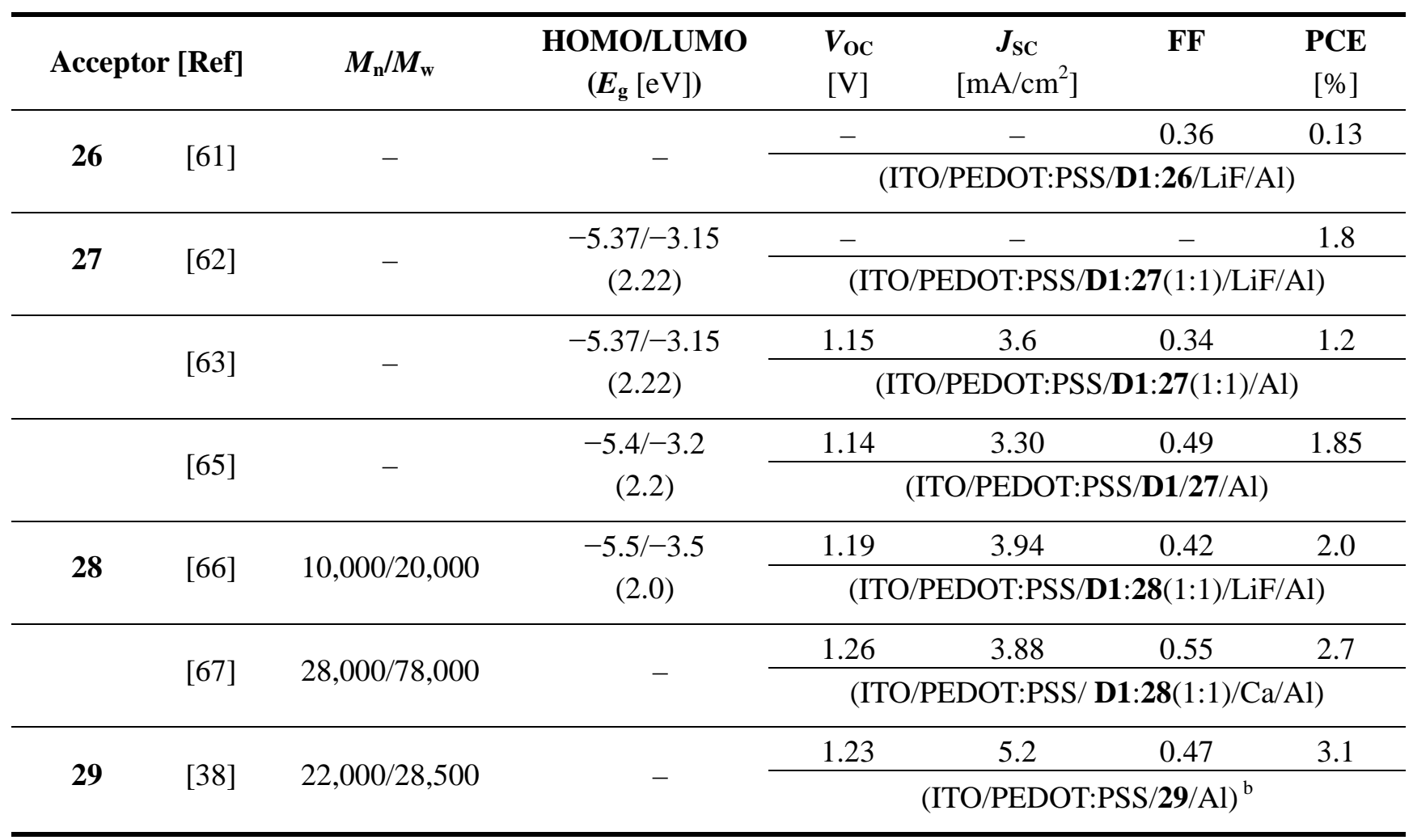

Notes: ${ }^{\mathrm{a}}$ Measured at AM $1.5 \mathrm{G} 100 \mathrm{~mW} / \mathrm{cm}^{2}$ unless indicated; ${ }^{\mathrm{b}}$ Measured at $97 \mathrm{~mW} / \mathrm{cm}^{2}$

\section{CN-substituted Polymer Acceptors}

In earlier studies, PPV derivatives were recognized as good hole-transporting materials in organic light-emitting diode (OLED) devices [68,69]. After introducing electron-withdrawing CN groups into the vinylene moiety of the PPV backbone, the polymers exhibited large electron affinity and were used as light emitters or electron transport layers in OLED devices [24]. The introduction of a CN group into other traditional p-type polymers such as D1 and polyfluorenes also altered the electronic properties of the resulting polymers for use as polymer acceptors in OPVs; a few examples are presented at the end of this section. The photophysical properties and device performance parameters of CN-substituted polymer acceptors (31-38) are summarized in Table 4. 
In 1995, Holmes and Friend et al. fabricated all-polymer photovoltaic cells composed of PPV derivatives. CN-substituted PPV, CN-PPV (30, Figure 7), was used as an electron acceptor with a poly(2-methoxy-5-(2'-ethyl-hexyloxy)-1,4-phenylenevinylene) (MEH-PPV, D14, Figure 8) polymer donor. The best performing device had an EQE of 6\% with a $V_{\mathrm{OC}}$ of $0.6 \mathrm{~V}$ [70]. Heeger et al. also introduced a CN-PPV derivative, denoted by MEH-CN-PPV (31, Figure 7), as an acceptor in OPV devices with a D14 donor, achieving PCE of up to 0.9\% [71]. Friend and co-workers utilized 31 as a polymer acceptor in laminate bi-layer solar cells using a polymer donor POPT (D15, Figure 8) that had increased spectral breadth, a lower-lying HOMO, and enhanced air stability compared to D1 [15]. Adding a small amount (2-5 wt\%) of D15 to the $\mathbf{3 1}$ layer increased the efficiency of the devices up to $1.9 \%$ compared to the low efficiency achieved with the bi-layer. Frechet et al. also fabricated bi-layer solar cells of D15/31, in which D15 was synthesized using the Grignard metathesis (GRIM) polymerization method, resulting in a high number-average molecular weight $\left(M_{\mathrm{n}}\right)$, low polydispersity index, and high regioregularity. Polymer 31 could be spin-coated directly on top of a D15 film using tetrahydrofuran or ethyl acetate as a solvent, neither of which dissolves D15, leading to laminated bi-layer devices [72]. A PCE of 2.0\% was achieved with the fabricated device after $2 \mathrm{~h}$ of post-annealing at $110{ }^{\circ} \mathrm{C}$. Subsequently, Gunes et al. introduced longer alkyl side chains in the CN-PPV derivatives, resulting in another CN-PPV derivative, DE119 (32, Figure 7). The BHJ solar cells were fabricated with D1 donor using various solvents such as chlorobenzene, toluene, and chloroform [73]. A PCE of 0.3\% was achieved using chlorobenzene as a casting solvent by employing a blend ratio of 1:2 (D1:32). Improved device performance (PCE of 0.34\%) was achieved in the inverted device structure with a $J_{\mathrm{SC}}$ of $0.86 \mathrm{~mA} / \mathrm{cm}^{2}$, a $V_{\mathrm{OC}}$ of $0.9 \mathrm{~V}$, and a FF of 0.44 .

Egbe et al. introduced electron-withdrawing acetylene groups into the CN-PPV derivative, resulting in polymer 33 (Figure 7) [74]. They fabricated blend and bi-layer OPV devices with 33 and poly[2,5-dimethoxy-1,4-phenylene-vinylene-2-methoxy-5-(2-ethylhexyloxy)-1,4-phenylene-vinylene] (M3EH-PPV, D16, Figure 8) as a polymer acceptor and a polymer donor, respectively. The maximal PCE of $0.65 \%$ was obtained with the bi-layer 33/D16 device. The rather low FF $(0.11-0.27)$ was ascribed to the low electron mobility induced by the acetylene group adjacent to the phenyl rings.

Another type of CN-PPV, developed by inserting an ether linkage into CN-PPV, denoted by CN-ether-PPV (34, Figure 7), was introduced by Horhold et al. BHJ solar cells with three different electrode configurations were fabricated using D16 and 34 polymer blend (ITO/TiO $/$ polymer $^{2}$ blend/Au, ITO/PEDOT/polymer blend/Al, and ITO/PEDOT/polymer blend/Ca) [75]. The maximal PCE of $1.0 \%$ was obtained by using a Ca electrode with low work function. Later, the improved PCE of $1.7 \%$ was reported using the same donor and acceptor materials by completing the device with evaporated $\mathrm{Ca} / \mathrm{Al}$ [76]. Vertical phase separation derived from an excess of $\mathbf{3 4}$ at the top and an excess of D16 at the bottom of the blend layer was proposed, which was derived from the lower solubility of D16 in chlorobenzene relative to 34. The device utilizing the blend exhibited a higher PCE than that of bi-layer devices, and the performance of the devices was enhanced by annealing due to increased ordering of the chains in D16. More recently, D16:34 blend films were fabricated using different solvents or a solvent mixture of 1,2,4-trichlorobenzene and chloroform to evaluate the interrelation in polymer-polymer photovoltaic devices [77]. Devices coated with mixtures of 1,2,4-trichlorobenzene and chloroform had a better PCE (1.42\%) than that coated with chloroform (0.62\%). Compared to chloroform, 1,2,4-trichlorobenzene was a more selective solvent because of its high boiling point. 
Subsequent to the synthesis of the CN-substituted polyfluorenes PF1CVTP (35, Figure 7) for use in OLEDs [78], Koetse et al. fabricated BHJ solar cells using a blend of 35 and MDMO-PPV (D17, Figure 8) as an acceptor and a donor, respectively [79]. A PCE of 1.5\% was achieved with a $J_{\text {SC }}$ of $3.0 \mathrm{~mA} / \mathrm{cm}^{2}$, a $V_{\text {OC }}$ of $1.40 \mathrm{~V}$, and a FF of 0.37 .

Table 4. CN-substituted polymer acceptors ${ }^{\mathrm{a}}$.

\begin{tabular}{|c|c|c|c|c|c|c|c|}
\hline \multicolumn{2}{|c|}{ Acceptor [Ref] } & \multirow{3}{*}{$\begin{array}{c}M_{\mathrm{n}} / \boldsymbol{M}_{\mathrm{w}} \\
-\end{array}$} & \multirow{3}{*}{$\begin{array}{c}\text { HOMO/LUMO } \\
\begin{array}{c}\left(\boldsymbol{E}_{\mathrm{g}}[\mathrm{eV}]\right) \\
- \\
(\sim 2)\end{array}\end{array}$} & \multirow{3}{*}{$\begin{array}{c}V_{\mathbf{O C}} \\
{[\mathrm{V}]} \\
- \\
\end{array}$} & \multirow{2}{*}{$\begin{array}{c}\boldsymbol{J}_{\mathrm{SC}} \\
{\left[\mathrm{mA} / \mathrm{cm}^{2}\right]}\end{array}$} & \multirow{2}{*}{$\begin{array}{c}\text { FF } \\
- \\
\end{array}$} & \multirow{2}{*}{$\begin{array}{r}\text { PCE } \\
{[\%]}\end{array}$} \\
\hline \multirow{6}{*}{31} & \multirow{2}{*}{ [71] } & & & & & & \\
\hline & & & & & \multicolumn{3}{|c|}{$(\mathrm{ITO} / \mathrm{D} 14: 31(1: 1) / \mathrm{Ca})^{\mathrm{b}}$} \\
\hline & \multirow{2}{*}[15]{} & \multirow{2}{*}{-} & \multirow{2}{*}{-} & 2.2 & - & - & 1.9 \\
\hline & & & & \multicolumn{4}{|c|}{$(\mathrm{Au} / \mathrm{PEDOT}: \mathrm{PSS} / \mathbf{D 1 5} / \mathbf{3 1} / \mathrm{Ca} \text { or } \mathrm{Al})^{\mathrm{c}}$} \\
\hline & \multirow{2}{*}[72]{} & \multirow{2}{*}{$16,000 / 72,000$} & $-1-3.7$ & - & - & - & 2.0 \\
\hline & & & - & \multicolumn{4}{|c|}{ (ITO/PEDOT:PSS/ D15/31/LiF/Al) } \\
\hline \multirow{2}{*}{32} & \multirow{2}{*}{ [73] } & \multirow{2}{*}{$8,000 / 19,000$} & $-5.97 /-3.48$ & 0.9 & 0.86 & 0.44 & 0.34 \\
\hline & & & $(2.49)$ & \multicolumn{4}{|c|}{ (Inverted structure) } \\
\hline \multirow{2}{*}{33} & \multirow{2}{*}{ [74] } & \multirow{2}{*}{$35,100 / 119,000$} & $-5.7 /-3.35$ & 1.52 & 1.4 & 0.27 & 0.65 \\
\hline & & & $(2.35)$ & \multicolumn{4}{|c|}{ (ITO/PEDOT:PSS/D16/33/Ca/Al) } \\
\hline \multirow{6}{*}{34} & \multirow{2}{*}[75]{} & \multirow{2}{*}{-} & \multirow{2}{*}{-} & 1.0 & 3.2 & 0.25 & 1.0 \\
\hline & & & & \multicolumn{4}{|c|}{ 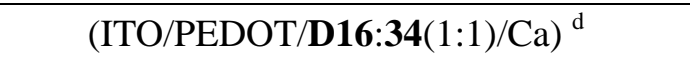 } \\
\hline & \multirow{2}{*}[76]{} & \multirow{2}{*}{-} & ${ }_{-}$ & 1.36 & 3.57 & 0.35 & 1.7 \\
\hline & & & - & & PEDOT/D1 & $(1: 1) / C$ & \\
\hline & [77] & - & - & 1.31 & 2.5 & 0.44 & 1.42 \\
\hline & {$[1 / 1]$} & $-1 \angle 0,000$ & - & & PEDOT/D1 & $1: 1) / C$ & \\
\hline 35 & [79] & $\ldots$ & - & 1.40 & 3.0 & 0.37 & 1.5 \\
\hline (5) & 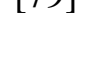 & 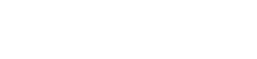 & 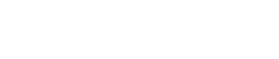 & & PEDOT:PS & 7:35/L & \\
\hline 36 & [80] & - & $-5.75 /-3.65$ & 0.85 & 3.14 & 0.29 & 0.8 \\
\hline 30 & [00] & - & (2.1) & (IT & DOT:PSS/I & $36(1: 1)$ & Al) \\
\hline 37 & [811 & $26900 / 61800$ & $-6.1 /-3.6$ & 0.62 & 0.09 & 0.26 & 0.014 \\
\hline 31 & {$[01]$} & $20,900 / 01,000$ & (2.5) & (ITC & DOT:PSS/I & $7(1: 2)$ & Al) \\
\hline & & & & 0.59 & 0.02 & 0.27 & 0.003 \\
\hline & & & & (ITC & DOT:PSS/I & $7(2: 1)$ & Al) \\
\hline 38 & [82] & - & - & 0.74 & 0.28 & 0.33 & 0.07 \\
\hline 50 & [02] & - & - & & EDOT:PSS/ & $8(1: 1)$ & \\
\hline
\end{tabular}

Notes: ${ }^{a}$ Measured at AM 1.5G $100 \mathrm{~mW} / \mathrm{cm}^{2}$ unless indicated; ${ }^{\mathrm{b}}$ Measured at $430 \mathrm{~nm}$ from $20 \mathrm{~mW} / \mathrm{cm}^{2}$ to $1 \mu \mathrm{W} / \mathrm{cm}^{2}$;

${ }^{\mathrm{c}}$ Measured at $77 \mathrm{~mW} / \mathrm{cm}^{2}$; ${ }^{\mathrm{d}}$ Measured at $80 \mathrm{~mW} / \mathrm{cm}^{2}$; ${ }^{\mathrm{e}}$ Measured at $90 \mathrm{~mW} / \mathrm{cm}^{2}$ 
Figure 7. Molecular structures of CN-substituted polymer acceptors (30-38).

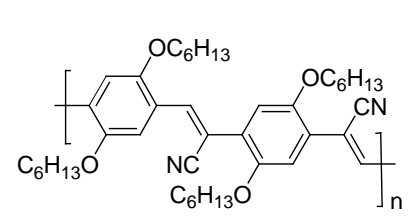

$30 \mathrm{CN}-\mathrm{PPV}$

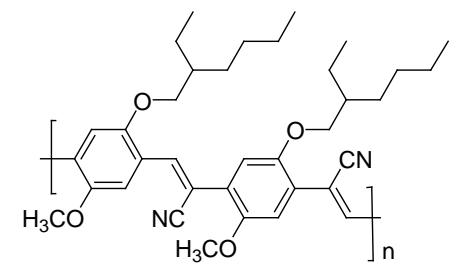

31 MEH-CN-PPV

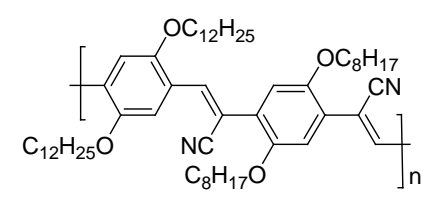

32 DE119

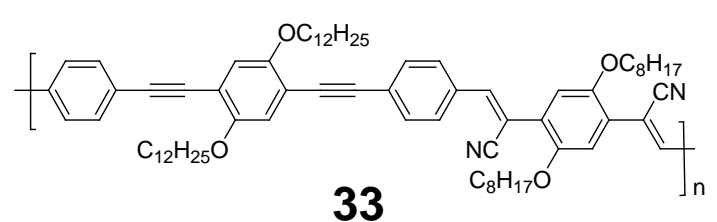

33

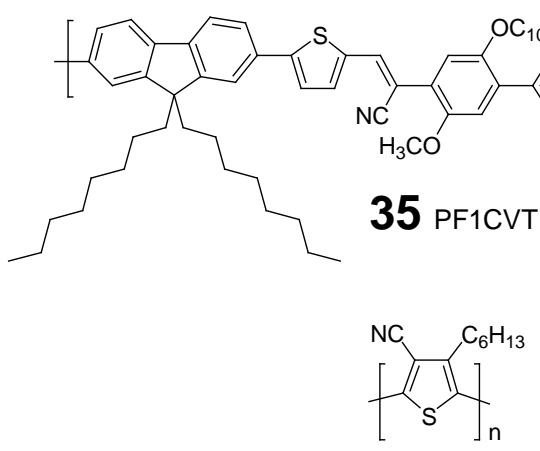

37 P3CN4HT

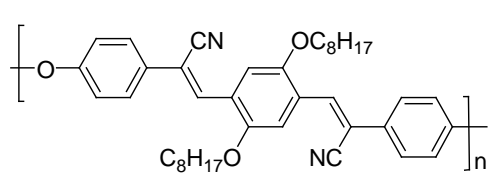

34 CN-ether-PPV

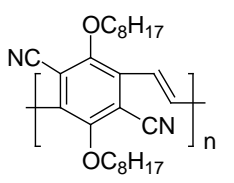

36 DOCN-PPV

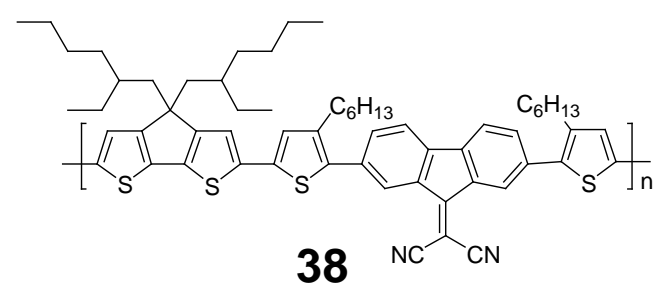

Figure 8. Molecular structures of polymer donors (D14-D19).

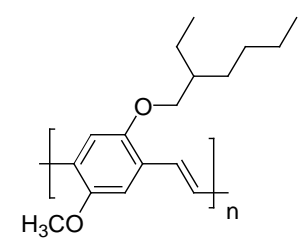

D14 MEH-PPV

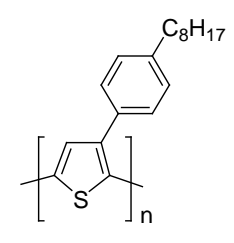

D15 РОРT

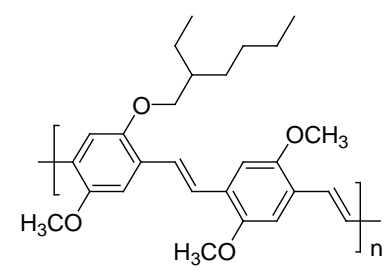

D16 МЗЕН-PPV

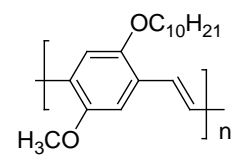

D17 MDMO-PPV

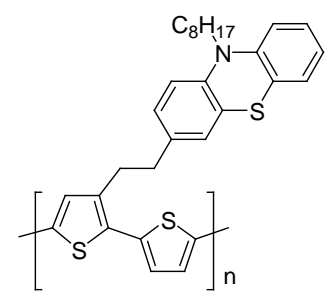

D18 PTZV-PT

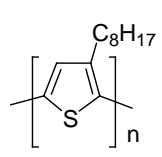

D19 Рзот

Another type of CN-PPV derivative acceptor, DOCN-PPV (36, Figure 7), was also reported by Li and co-workers, where 36 was directly CN-substituted on the phenyl rings [80]. Polymer 36 was blended with a PTZV-PT (D18, Figure 8) donor and applied to BHJ solar cells; post-annealing of the devices at $120^{\circ} \mathrm{C}$ enhanced the PCE from $0.41-0.8 \%$. 
The electron-withdrawing CN group was also introduced into other traditional $p$-type polymers such as D1 and polyfluorenes. Kallitsis's group synthesized poly(3-cyano-4-hexylthiophene) (P3CN4HT, 37, Figure 7) by introducing a CN-substituent into the thiophene ring of polymer D1 [81]. The HOMO and LUMO energy levels of 37 (-6.1 and -3.6 eV, respectively) were lowered compared to $\mathbf{D 1}$ ( -5.2 and $-3.0 \mathrm{eV}$, respectively). The devices were fabricated with two polymer donors, i.e., D17 and poly(3-octylthiophene) (P3OT, D19, Figure 8), giving rise to a low PCE of less than 0.015\%.

Recently, Seki et al. introduced three dicyanofluorene-based D-A type copolymers including 38 (Figure 6) [82]. Strong absorption bands were observed for all polymers, and a red-shift of the absorption spectra was induced by increasing the number of thiophene units in the polymer. The optimal PCE of $0.07 \%$ was achieved when the polymer acceptor $\mathbf{3 8}$ was blended with D1.

\section{Other Polymer Acceptors Containing Electron-Withdrawing Units}

In addition to the polymer acceptors mentioned above, several other polymer acceptors have been developed that contain other electron-deficient units such as thiazole, DPP, and fullerene in order to induce $n$-type features in the polymer. Such units are widely used as electron-deficient units in D-A type low band-gap donor materials [83]. The photophysical properties and device performance parameters of other polymer acceptors containing electron-withdrawing units (39-44) are summarized in Table 5.

Table 5. Other polymer acceptors containing electron-withdrawing units ${ }^{\mathrm{a}}$.

\begin{tabular}{|c|c|c|c|c|c|c|c|c|}
\hline \multicolumn{2}{|c|}{ Acceptor [ref] } & $\begin{array}{l}M_{\mathrm{n}} \\
M_{\mathrm{w}}\end{array}$ & $\begin{array}{l}\text { mobility, } \boldsymbol{\mu}_{\mathbf{e}} \\
{\left[\mathrm{cm}^{2} \mathrm{~V}^{-1} \mathrm{~s}^{-1}\right]}\end{array}$ & $\begin{array}{c}\text { HOMO/LUMO } \\
\left(E_{\mathrm{g}}[\mathrm{eV}]\right)\end{array}$ & $\begin{array}{l}V_{\mathbf{O C}} \\
{[\mathrm{V}]}\end{array}$ & $\begin{array}{c}\boldsymbol{J}_{\mathrm{SC}} \\
{\left[\mathrm{mA} / \mathrm{cm}^{2}\right]}\end{array}$ & FF & $\begin{array}{l}\text { PCE } \\
{[\%]} \\
\end{array}$ \\
\hline \multirow{2}{*}{39} & \multirow{2}{*}{ [84] } & 14,300 & \multirow{2}{*}{$1.1 \times 10^{-2 b}$} & \multirow{2}{*}{$\begin{array}{c}-5.43 /-3.45 \\
(1.98)\end{array}$} & 1.00 & 2.60 & 0.45 & 1.18 \\
\hline & & 26,000 & & & \multicolumn{4}{|c|}{$\left(\mathrm{ITO} / \mathrm{ZnO} / \mathbf{D 1}: 39(1.5: 1) / \mathrm{MoO}_{3} / \mathrm{Ag}\right)$} \\
\hline \multirow{2}{*}{40} & \multirow{2}{*}[84]{} & 26,100 & \multirow{2}{*}{$2.9 \times 10^{-4 b}$} & \multirow{2}{*}{$\begin{array}{c}-5.28 /-3.21 \\
(2.07)\end{array}$} & 0.9 & 1.5 & 0.43 & 0.58 \\
\hline & & 39,200 & & & \multicolumn{4}{|c|}{$\left(\mathrm{ITO} / \mathrm{ZnO} / \mathbf{D 1}: 40(1.5: 1) / \mathrm{MoO}_{3} / \mathrm{Ag}\right)$} \\
\hline \multirow{2}{*}{41} & \multirow{2}{*}{ [85] } & 16,600 & \multirow{2}{*}{$3 \times 10^{-9 c}$} & \multirow{2}{*}{$\begin{array}{c}-5.66 /-3.61 \\
(2.1)\end{array}$} & 0.94 & 0.68 & 0.22 & 0.14 \\
\hline & & 41,500 & & & \multicolumn{4}{|c|}{ (ITO/PEDOT:PSS/D1:41(1:1)/LiF/Al) } \\
\hline \multirow{2}{*}{42} & \multirow{2}{*}[85]{} & 11,800 & \multirow{2}{*}{$1 \times 10^{-11 c}$} & \multirow{2}{*}{$\begin{array}{c}-5.58 /-3.58 \\
(2.0)\end{array}$} & 0.90 & 0.44 & 0.27 & 0.11 \\
\hline & & 23,600 & & & \multicolumn{4}{|c|}{ (ITO/PEDOT:PSS/D1:42(1:1)/LiF/Al) } \\
\hline \multirow{2}{*}{43} & \multirow{2}{*}[85]{} & 10,500 & \multirow{2}{*}{$5 \times 10^{-10 c}$} & \multirow{2}{*}{$\begin{array}{c}-5.43 /-3.71 \\
(1.75)\end{array}$} & 0.90 & 1.63 & 0.25 & 0.37 \\
\hline & & 23,100 & & & \multicolumn{4}{|c|}{ (ITO/PEDOT:PSS/D1:43(1:1)/LiF/Al) } \\
\hline \multirow{2}{*}{44} & \multirow{2}{*}[86]{} & 8,700 & \multirow{2}{*}{-} & \multirow{2}{*}{$-1-3.67$} & 0.63 & 4.45 & 0.54 & 1.5 \\
\hline & & 12,100 & & & \multicolumn{4}{|c|}{ (ITO/PEDOT:PSS/D1:44(1:0.45)/Ca/Al) } \\
\hline
\end{tabular}

Notes: ${ }^{a}$ Measured at AM 1.5G 100mW/cm²; ${ }^{b}$ By OFET measurement; ${ }^{\mathrm{c}}$ By SCLC measurement

Pei and co-workers synthesized a polymer acceptor 39 (Figure 9) based on thiazole-containing, electron-deficient 4,7-di(thiazol-2-yl)-2,1,3-benzothiadiazole (DTABT) [84]. The acceptor 40 (Figure 9) based on 4,7-di(thien-2-yl)-2,1,3-benzothiadiazole (DTBT) was also synthesized for comparison with DTABT. The BHJ solar cells based on 39 achieved a two-fold higher PCE (1.18\%) 
than that of $40(0.58 \%)$ when blended with a D1 donor. The energy of the HOMO and LUMO levels of 39 were lowered by the strong electron withdrawing property of DTABT which facilitated high electron mobility, resulting in increased $J_{\mathrm{SC}}$. Furthermore, the device employing $\mathbf{3 9}$ displayed better miscibility with D1, thus exhibiting less surface roughness.

Figure 9. Molecular structures of polymer acceptors containing electron-withdrawing units (39-44).
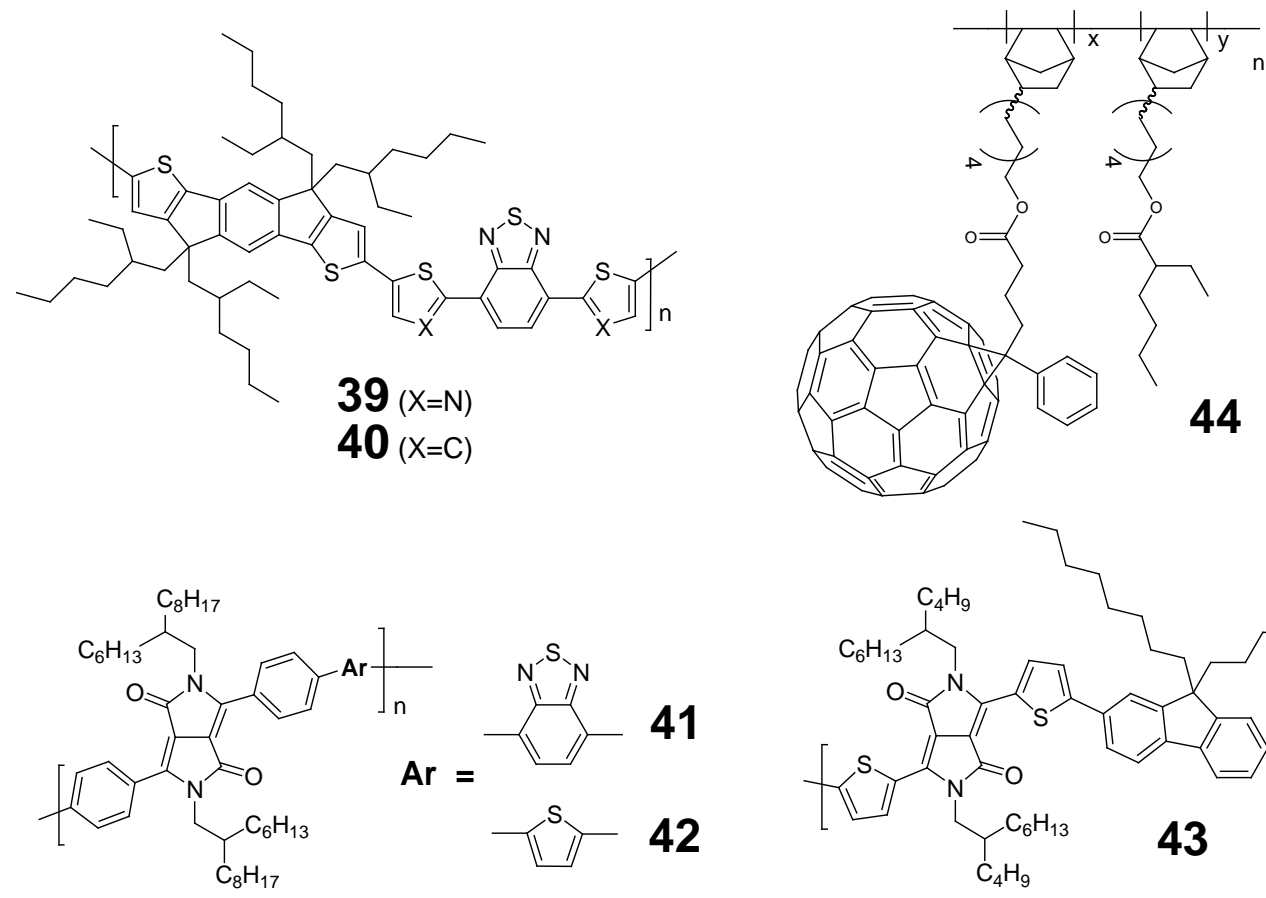

42

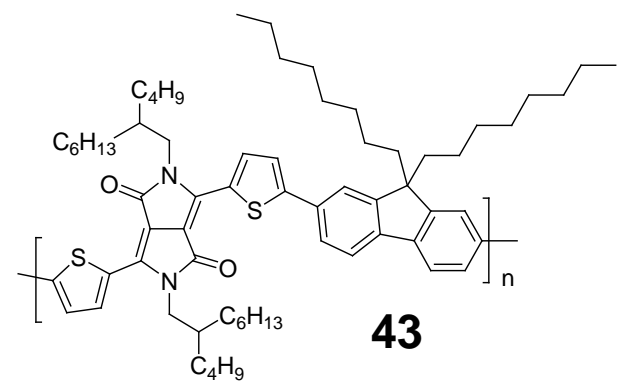

Janssen et al. synthesized the new DPP-based acceptors, 41, 42, and 43 (Figure 9) [85]. The DPP unit is a strong withdrawing unit and DPP-based D-A type polymeric and small-molecule donor materials have shown promising performance in BHJ solar cells. The three acceptors gave rise to PCEs in the range of $0.11 \%-0.37 \%$ when coupled with a $\mathbf{D} 1$ donor in BHJ solar cells. The $V_{\mathrm{OC}}$ values were relatively high $\left(\geq 0.9 \mathrm{~V}\right.$ ), whereas the low FF and $J_{\mathrm{SC}}$ decreased the performance of the devices because of low electron mobility.

Do and co-workers presented novel polynorbornenes (44, Figure 9) with 50 mol\% $\mathrm{PC}_{61} \mathrm{BM}$ as an acceptor that exhibited high thermal stability $\left(T_{\mathrm{d}}=437^{\circ} \mathrm{C}\right)$ [86]. The device fabricated with the D1:44 blend achieved a PCE of 1.5\%. The ratio of 1:0.45 (D:A, w/w) was appropriate for the BHJ solar cell and the $V_{\mathrm{OC}}$ values were similar despite variation of the ratio of $\mathbf{4 4}$. Recently, they also reported the syntheses of polynorbornenes with a pendant $\mathrm{PC}_{61} \mathrm{BM}$ unit via ring-opening metathesis for use as polymer acceptors in OPVs [87].

In addition, various electron-deficient units such as oxadiazole and quinoxaline could also be used as building blocks for polymer acceptors [50,88,89]. Relatively low PCEs (maximum of 0.07\%) were achieved with these species; however, the research is still in progress, and a range of various possibilities for developing new polymer acceptors remains open. 


\section{Conclusions}

This review focused on various n-type polymers for use as acceptors in OPVs. The polymer acceptors have been utilized in all-polymer solar cells with various polymer donors. Herein, the polymer acceptors were classified into four sections depending on the molecular structures. The rylene diimide-based polymer acceptors offer the advantages of good thermal, chemical, and photochemical stability. This group also exhibits high electron affinity and high electron mobility due to the electron accepting imide group in the backbone. The rylene diimide-based polymer acceptors such as PDI, NDI, and DTCDI-based polymer materials were subdivided according to their structures. The solubility and molecular shapes of the PDI-based polymers varied based on the mode of substitution of PDI, i.e., in the bay- or imide-positions. Fluorene and BT-based $n$-type polymers have also found application as polymer acceptors, having an ambipolar nature of electron donor and acceptor, based on the counterpart materials and are characterized by high electron mobility and broad UV absorption spectra. CN-substitution on the inherently electron-rich polymer backbones of PPVs, polythiophene, and polyfluorene or the introduction of electron-withdrawing moieties such as DPP, thiazole, and fullerene as co-monomer units also resulted in $n$-type polymer acceptors with high electron affinities.

Many of the reports referenced in this review deal with various strategies for the design and synthesis of new polymer structures as well as optimization of device processing conditions to achieve enhanced device performance. For use as electron acceptors, the polymers should possess the following features: (i) high electron mobility for electron transfer, (ii) good solubility achieved by long and/or branched alkyl side chains, (iii) high $M_{\mathrm{w}}$ to enhance conjugation length, (iv) adequate HOMO and LUMO energy levels modulating the band-gap for effective charge separation, (v) red-shifted UV absorption spectra for maximum absorption of solar energy, and (vi) sufficient aggregation with the use of a proper additive to increase the $\mathrm{D} / \mathrm{A}$ interface. To date, the best performance achieved with all-polymer solar cells is a PCE of 3.45\% using the PDI-based polymer acceptor. We believe continued research effort can reveal means of overcoming the limitations of the device performance based on polymer acceptors that are unresolved at the present stage. The balanced development of donor and acceptor materials may lead to the enhanced performance of solution-processable OPV cells and related applications need to be introduced in the market in the near future. We believe that this review provides a detailed insight for the design of new $n$-type polymer acceptors in future research.

\section{Acknowledgments}

This research was supported by Basic Science Research Program through the National Research Foundation of Korea (NRF) funded by the Ministry of Education, Science and Technology (2012R1A1A3005083).

\section{Conflicts of Interest}

The authors declare no conflict of interest. 


\section{References}

1. Parida, B.; Iniyan, S.; Goic, R. A review of solar photovoltaic technologies. Renew. Sust. Energ. Rev. 2011, 15, 1625-1636.

2. Dou, L.; You, J.; Hong, Z.; Xu, Z.; Li, G.; Street, R.A.; Yang, Y. 25th Anniversary Article: A Decade of Organic/Polymeric Photovoltaic Research. Adv. Mater. 2013, 25, 6642-6671.

3. Yue, D.; Khatav, P.; You, F.; Darling, S.B. Deciphering the uncertainties in life cycle energy and environmental analysis of organic photovoltaics. Energ. Environ. Sci. 2012, 5, 9163-9172.

4. Darling, S.B.; You, F. The case for organic photovoltaics. RSC Adv. 2013, 3, 17633-17648.

5. Boudreault, P.-L.T.; Najari, A.; Leclerc, M. Processable Low-Bandgap Polymers for Photovoltaic Applications. Chem. Mater. 2010, 23, 456-469.

6. Liao, H.-C.; Ho, C.-C.; Chang, C.-Y.; Jao, M.-H.; Darling, S.B.; Su, W.-F. Additives for morphology control in high-efficiency organic solar cells. Mater. Today 2013, 16, 326-336.

7. You, J.; Dou, L.; Hong, Z.; Li, G.; Yang, Y. Recent trends in polymer tandem solar cells research. Prog. Polym. Sci. 2013, 38, 1909-1928.

8. Chen, L.-M.; Hong, Z.; Li, G.; Yang, Y. Recent Progress in Polymer Solar Cells: Manipulation of Polymer: Fullerene Morphology and the Formation of Efficient Inverted Polymer Solar Cells. Adv. Mater. 2009, 21, 1434-1449.

9. Yi, C.; Gong, X. Towards high performance inverted polymer solar cells. Curr. Opin. Chem. Eng. 2013, 2, 125-131.

10. Chen, W.; Nikiforov, M.P.; Darling, S.B. Morphology characterization in organic and hybrid solar cells. Energ. Environ. Sci. 2012, 5, 8045-8074.

11. Nikiforov, M.P.; Lai, B.; Chen, W.; Chen, S.; Schaller, R.D.; Strzalka, J.; Maser, J.; Darling, S.B. Detection and role of trace impurities in high-performance organic solar cells. Energ. Environ. Sci. 2013, 6, 1513-1520.

12. Heliatek. Available online: http://www.heliatek.com/ (accessed on 7 February 2014).

13. Tang, C.W. Two-layer organic photovoltaic cell. Appl. Phys. Lett. 1986, 48, 183-185.

14. Jenekhe, S.A.; Yi, S. Efficient photovoltaic cells from semiconducting polymer heterojunctions. Appl. Phys. Lett. 2000, 77, 2635-2637.

15. Granstrom, M.; Petritsch, K.; Arias, A.C.; Lux, A.; Andersson, M.R.; Friend, R.H. Laminated fabrication of polymeric photovoltaic diodes. Nature 1998, 395, 257-260.

16. Yu, G.; Gao, J.; Hummelen, J.C.; Wudl, F.; Heeger, A.J. Polymer Photovoltaic Cells: Enhanced Efficiencies via a Network of Internal Donor-Acceptor Heterojunctions. Science 1995, 270, 1789-1791.

17. Lee, J.K.; Ma, W.L.; Brabec, C.J.; Yuen, J.; Moon, J.S.; Kim, J.Y.; Lee, K.; Bazan, G.C.; Heeger, A.J. Processing Additives for Improved Efficiency from Bulk Heterojunction Solar Cells. J. Am. Chem. Soc. 2008, 130, 3619-3623.

18. Zhicai, H.; Chengmei, Z.; Shijian, S.; Miao, X.; Hongbin, W.; Yong, C. Enhanced power-conversion efficiency in polymer solar cells using an inverted device structure. Nat. Photonics 2012, 6, 591-595.

19. Guo, X.; Baumgarten, M.; Müllen, K. Designing $\pi$-conjugated polymers for organic electronics. Prog. Polym. Sci. 2013, 38, 1832-1908. 
20. Zhu, Z.; Waller, D.; Gaudiana, R.; Morana, M.; Mühlbacher, D.; Scharber, M.; Brabec, C. Panchromatic Conjugated Polymers Containing Alternating Donor/Acceptor Units for Photovoltaic Applications. Macromolecules 2007, 40, 1981-1986.

21. Hou, J.; Chen, H.-Y.; Zhang, S.; Li, G.; Yang, Y. Synthesis, Characterization, and Photovoltaic Properties of a Low Band Gap Polymer Based on Silole-Containing Polythiophenes and 2,1,3-Benzothiadiazole. J. Am. Chem. Soc. 2008, 130, 16144-16145.

22. Dou, L.; Chen, C.-C.; Yoshimura, K.; Ohya, K.; Chang, W.-H.; Gao, J.; Liu, Y.; Richard, E.; Yang, Y. Synthesis of 5H-Dithieno[3,2-b:2',3'-d]pyran as an Electron-Rich Building Block for Donor-Acceptor Type Low-Bandgap Polymers. Macromolecules 2013, 46, 3384-3390.

23. Zhou, J.; Zuo, Y.; Wan, X.; Long, G.; Zhang, Q.; Ni, W.; Liu, Y.; Li, Z.; He, G.; Li, C.; Kan, B.; Li, M.; Chen, Y. Solution-Processed and High-Performance Organic Solar Cells Using Small Molecules with a Benzodithiophene Unit. J. Am. Chem. Soc. 2013, 135, 8484-8487.

24. Sonar, P.; Fong Lim, J.P.; Chan, K.L. Organic non-fullerene acceptors for organic photovoltaics. Energ. Environ. Sci. 2011, 4, 1558-1574.

25. Lin, Y.; Li, Y.; Zhan, X. Small molecule semiconductors for high-efficiency organic photovoltaics. Chem. Soc. Rev. 2012, 41, 4245-4272.

26. Kozma, E.; Catellani, M. Perylene diimides based materials for organic solar cells. Dyes Pigm. 2013, 98, 160-179.

27. Qu, S.; Tian, H. Diketopyrrolopyrrole (DPP)-based materials for organic photovoltaics. Chem. Commun. 2012, 48, 3039-3051.

28. Cheng, P.; Ye, L.; Zhao, X.; Hou, J.; Li, Y.; Zhan, X. Binary additives synergistically boost the efficiency of all-polymer solar cells up to 3.45\%. Energ. Environ. Sci. 2014, doi:10.1039/c3ee43041c.

29. Zhang, X.; Lu, Z.; Ye, L.; Zhan, C.; Hou, J.; Zhang, S.; Jiang, B.; Zhao, Y.; Huang, J.; Zhang, S.; Liu, Y.; Shi, Q.; Liu, Y.; Yao, J. A Potential Perylene Diimide Dimer-Based Acceptor Material for Highly Efficient Solution-Processed Non-Fullerene Organic Solar Cells with 4.03\% Efficiency. Adv. Mater. 2013, 25, 5791-5797.

30. Facchetti, A. Polymer donor-polymer acceptor (all-polymer) solar cells. Mater. Today 2013, 16, 123-132.

31. Darling, S.B. Block copolymers for photovoltaics. Energ. Environ. Sci. 2009, 2, 1266-1273.

32. Segalman, R.A.; McCulloch, B.; Kirmayer, S.; Urban, J.J. Block Copolymers for Organic Optoelectronics. Macromolecules 2009, 42, 9205-9216.

33. Bang, J.; Jeong, U.; Ryu, D.Y.; Russell, T.P.; Hawker, C.J. Block Copolymer Nanolithography: Translation of Molecular Level Control to Nanoscale Patterns. Adv. Mater. 2009, 21, 4769-4792.

34. Sommer, M.; Huettner, S.; Thelakkat, M. Donor-acceptor block copolymers for photovoltaic applications. J. Mater. Chem. 2010, 20, 10788-10797.

35. Zhang, Q.; Cirpan, A.; Russell, T.P.; Emrick, T. Donor-Acceptor Poly(thiophene-block-perylene diimide) Copolymers: Synthesis and Solar Cell Fabrication. Macromolecules 2009, 42, 1079-1082.

36. Sommer, M.; Hüttner, S.; Steiner, U.; Thelakkat, M. Influence of molecular weight on the solar cell performance of double-crystalline donor-acceptor block copolymers. Appl. Phys. Lett. 2009, 95, 183308:1-183308:3. 
37. Nakabayashi, K.; Mori, H. All-Polymer Solar Cells Based on Fully Conjugated Block Copolymers Composed of Poly(3-hexylthiophene) and Poly(naphthalene bisimide) Segments. Macromolecules 2012, 45, 9618-9625.

38. Guo, C.; Lin, Y.-H.; Witman, M.D.; Smith, K.A.; Wang, C.; Hexemer, A.; Strzalka, J.; Gomez, E.D.; Verduzco, R. Conjugated Block Copolymer Photovoltaics with near 3\% Efficiency through Microphase Separation. Nano Lett. 2013, 13, 2957-2963.

39. Zhou, W.; Zhang, Z.-G.; Ma, L.; Li, Y.; Zhan, X. Dithienocoronene diimide based conjugated polymers as electron acceptors for all-polymer solar cells. Sol. Energ. Mat. Sol. C. 2013, 112, 13-19.

40. Sommer, M. Conjugated polymers based on naphthalene diimide for organic electronics. J. Mater. Chem. C 2014, doi:10.1039/c3tc31755b.

41. Zhan, X.; Tan, Z.; Domercq, B.; An, Z.; Zhang, X.; Barlow, S.; Li, Y.; Zhu, D.; Kippelen, B.; Marder, S.R. A High-Mobility Electron-Transport Polymer with Broad Absorption and Its Use in Field-Effect Transistors and All-Polymer Solar Cells. J. Am. Chem. Soc. 2007, 129, 7246-7247.

42. Tan, Z.; Zhou, E.; Zhan, X.; Wang, X.; Li, Y.; Barlow, S.; Marder, S.R. Efficient all-polymer solar cells based on blend of tris(thienylenevinylene)-substituted polythiophene and poly[perylene diimide-alt-bis(dithienothiophene)]. Appl. Phys. Lett. 2008, 93, 073309:1-073309:3.

43. Zhan, X.; Tan, Z.; Zhou, E.; Li, Y.; Misra, R.; Grant, A.; Domercq, B.; Zhang, X.-H.; An, Z.; Zhang, X.; Barlow, S.; Kippelen, B.; Marder, S.R. Copolymers of perylene diimide with dithienothiophene and dithienopyrrole as electron-transport materials for all-polymer solar cells and field-effect transistors. J. Mater. Chem. 2009, 19, 5794-5803.

44. Liao, X.-X.; Zhao, X.; Zhang, Z.-G.; Wang, H.-Q.; Zhan, X.; Li, Y.; Wang, J.; Zheng, J.-C. All-polymer solar cells based on side-chain-isolated polythiophenes and poly(perylene diimidealt-dithienothiophene). Sol. Energ. Mat. Sol. C. 2013, 117, 336-342.

45. Zhou, E.; Tajima, K.; Yang, C.; Hashimoto, K. Band gap and molecular energy level control of perylene diimide-based donor-acceptor copolymers for all-polymer solar cells. J. Mater. Chem. 2010, 20, 2362-2368.

46. Zhou, E.; Cong, J.; Wei, Q.; Tajima, K.; Yang, C.; Hashimoto, K. All-Polymer Solar Cells from Perylene Diimide Based Copolymers: Material Design and Phase Separation Control. Angew. Chem. Int. Ed. 2011, 50, 2799-2803.

47. Neuteboom, E.E.; Meskers, S.C.; van Hal, P.A.; van Duren, J.K.; Meijer, E.W.; Janssen, R.A.; Dupin, H.; Pourtois, G.; Cornil, J.; Lazzaroni, R.; Brédas, J.-L.; Beljonne, D. Alternating Oligo(p-phenylene vinylene)_Perylene Bisimide Copolymers: Synthesis, Photophysics, and Photovoltaic Properties of a New Class of Donor-Acceptor Materials. J. Am. Chem. Soc. 2003, 125, 8625-8638.

48. Mikroyannidis, J.A.; Stylianakis, M.M.; Sharma, G.D.; Balraju, P.; Roy, M.S. A Novel Alternating Phenylenevinylene Copolymer with Perylene Bisimide Units: Synthesis, Photophysical, Electrochemical, and Photovoltaic Properties. J. Phys. Chem. C 2009, 113, 7904-7912.

49. Liang, Z.; Cormier, R.A.; Nardes, A.M.; Gregg, B.A. Developing perylene diimide based acceptor polymers for organic photovoltaics. Synt. Met. 2011, 161, 1014-1021. 
50. Alam, M.M.; Jenekhe, S.A. Efficient Solar Cells from Layered Nanostructures of Donor and Acceptor Conjugated Polymers. Chem. Mater. 2004, 16, 4647-4656.

51. Fabiano, S.; Chen, Z.; Vahedi, S.; Facchetti, A.; Pignataro, B.; Loi, M.A. Role of photoactive layer morphology in high fill factor all-polymer bulk heterojunction solar cells. J. Mater. Chem. 2011, 21, 5891-5896.

52. Moore, J.R.; Albert-Seifried, S.; Rao, A.; Massip, S.; Watts, B.; Morgan, D.J.; Friend, R.H.; McNeill, C.R.; Sirringhaus, H. Polymer Blend Solar Cells Based on a High-Mobility Naphthalenediimide-Based Polymer Acceptor: Device Physics, Photophysics and Morphology. Adv. Energy Mater. 2011, 1, 230-240.

53. Schubert, M.; Dolfen, D.; Frisch, J.; Roland, S.; Steyrleuthner, R.; Stiller, B.; Chen, Z.; Scherf, U.; Koch, N.; Facchetti, A.; Neher, D. Influence of Aggregation on the Performance of All-Polymer Solar Cells Containing Low-Bandgap Naphthalenediimide Copolymers. Adv. Energy Mater. 2012, 2, 369-380.

54. Hwang, Y.-J.; Ren, G.; Murari, N.M.; Jenekhe, S.A. n-Type Naphthalene Diimide-Biselenophene Copolymer for All-Polymer Bulk Heterojunction Solar Cells. Macromolecules 2012, 45, 9056-9062.

55. Earmme, T.; Hwang, Y.-J.; Murari, N.M.; Subramaniyan, S.; Jenekhe, S.A. All-Polymer Solar Cells with 3.3\% Efficiency Based on Naphthalene Diimide-Selenophene Copolymer Acceptor. J. Am. Chem. Soc. 2013, 135, 14960-14963.

56. Yuan, M.; Durban, M.M.; Kazarinoff, P.D.; Zeigler, D.F.; Rice, A.H.; Segawa, Y.; Luscombe, C.K. Synthesis and characterization of fused-thiophene containing naphthalene diimide $n$-type copolymers for organic thin film transistor and all-polymer solar cell applications. J. Polym. Sci. A Polym. Chem. 2013, 51, 4061-4069.

57. Chen, S.-C.; Zheng, Q.; Zhang, Q.; Cai, D.; Wang, J.; Yin, Z.; Tang, C. Tuning the frontier molecular orbital energy levels of n-type conjugated copolymers by using angular-shaped naphthalene tetracarboxylic diimides, and their use in all-polymer solar cells with high open-circuit voltages. J. Polym. Sci. A Polym. Chem. 2013, 51, 1999-2005.

58. He, Y.; Gong, S.; Hattori, R.; Kanicki, J. High performance organic polymer light-emitting heterostructure devices. Appl. Phys. Lett. 1999, 74, 2265-2267.

59. Arias, A.C.; MacKenzie, J.D.; Stevenson, R.; Halls, J.J.M.; Inbasekaran, M.; Woo, E.P.; Richards, D.; Friend, R.H. Photovoltaic Performance and Morphology of Polyfluorene Blends: A Combined Microscopic and Photovoltaic Investigation. Macromolecules 2001, 34, 6005-6013.

60. Snaith, H.J.; Arias, A.C.; Morteani, A.C.; Silva, C.; Friend, R.H. Charge Generation Kinetics and Transport Mechanisms in Blended Polyfluorene Photovoltaic Devices. Nano Lett. 2002, 2, 1353-1357.

61. Kim, Y.; Cook, S.; Choulis, S.A.; Nelson, J.; Durrant, J.R.; Bradley, D.D.C. Organic Photovoltaic Devices Based on Blends of Regioregular Poly(3-hexylthiophene) and Poly(9,9-dioctylfluorene-co-benzothiadiazole). Chem. Mater. 2004, 16, 4812-4818.

62. McNeill, C.R.; Abrusci, A.; Zaumseil, J.; Wilson, R.; McKiernan, M.J.; Burroughes, J.H.; Halls, J.J.M.; Greenham, N.C.; Friend, R.H. Dual electron donor/electron acceptor character of a 
conjugated polymer in efficient photovoltaic diodes. Appl. Phys. Lett. 2007, 90, 193506:1-193506:3.

63. McNeill, C.R.; Halls, J.J.M.; Wilson, R.; Whiting, G.L.; Berkebile, S.; Ramsey, M.G.; Friend, R.H.; Greenham, N.C. Efficient Polythiophene/Polyfluorene Copolymer Bulk Heterojunction Photovoltaic Devices: Device Physics and Annealing Effects. Adv. Funct. Mater. 2008, 18, 2309-2321.

64. McNeill, C.R.; Abrusci, A.; Hwang, I.; Ruderer, M.A.; Müller-Buschbaum, P.; Greenham, N.C. Photophysics and Photocurrent Generation in Polythiophene/Polyfluorene Copolymer Blends. Adv. Funct. Mater. 2009, 19, 3103-3111.

65. He, X.; Gao, F.; Tu, G.; Hasko, D.; Hüttner, S.; Steiner, U.; Greenham, N.C.; Friend, R.H.; Huck, W.T.S. Formation of Nanopatterned Polymer Blends in Photovoltaic Devices. Nano Lett. 2010, 10, 1302-1307.

66. Mori, D.; Benten, H.; Kosaka, J.; Ohkita, H.; Ito, S.; Miyake, K. Polymer/Polymer Blend Solar Cells with 2.0\% Efficiency Developed by Thermal Purification of Nanoscale-Phase-Separated Morphology. ACS Appl. Mater. Inter. 2011, 3, 2924-2927.

67. Mori, D.; Benten, H.; Ohkita, H.; Ito, S.; Miyake, K. Polymer/Polymer Blend Solar Cells Improved by Using High-Molecular-Weight Fluorene-Based Copolymer as Electron Acceptor. ACS Appl. Mater. Inter. 2012, 4, 3325-3329.

68. Moratti, S.C.; Cervini, R.; Holmes, A.B.; Baigent, D.R.; Friend, R.H.; Greenham, N.C.; Grüner, J.; Hamer, P.J. High electron affinity polymers for LEDs. Synt. Met. 1995, 71, 2117-2120.

69. Greenham, N.C.; Moratti, S.C.; Bradley, D.D.C.; Friend, R.H.; Holmes, A.B. Efficient light-emitting diodes based on polymers with high electron affinities. Nature 1993, 365, 628-630.

70. Halls, J.J.M.; Walsh, C.A.; Greenham, N.C.; Marseglia, E.A.; Friend, R.H.; Moratti, S.C.; Holmes, A.B. Efficient photodiodes from interpenetrating polymer networks. Nature 1995, 376, 498-500.

71. Yu, G.; Heeger, A.J. Charge separation and photovoltaic conversion in polymer composites with internal donor/acceptor heterojunctions. J. Appl. Phys. 1995, 78, 4510-4515.

72. Holcombe, T.W.; Woo, C.H.; Kavulak, D.F.J.; Thompson, B.C.; Fréchet, J.M.J. All-Polymer Photovoltaic Devices of Poly(3-(4-n-octyl)-phenylthiophene) from Grignard Metathesis (GRIM) Polymerization. J. Am. Chem. Soc. 2009, 131, 14160-14161.

73. Cevik, E.; İlicali, D.; Egbe, D.A.M.; Günes, S. Bulk heterojunction and inverted type solar cells using a CN-PPV derivative. Sol. Energ. Mat. Sol. C. 2012, 98, 94-102.

74. Egbe, D.A.M.; Kietzke, T.; Carbonnier, B.; Mühlbacher, D.; Hörhold, H.-H.; Neher, D.; Pakula, T. Synthesis, Characterization, and Photophysical, Electrochemical, Electroluminescent, and Photovoltaic Properties of Yne-Containing CN-PPVs. Macromolecules 2004, 37, 8863-8873.

75. Breeze, A.J.; Schlesinger, Z.; Carter, S.A.; Tillmann, H.; Hörhold, H.H. Improving power efficiencies in polymer-polymer blend photovoltaics. Solar Sol. Energ. Mat. Sol. C. 2004, 83, 263-271.

76. Kietzke, T.; Hörhold, H.-H.; Neher, D. Efficient Polymer Solar Cells Based on M3EHPV. Chem. Mater. 2005, 17, 6532-6537. 
77. Yin, C.; Schubert, M.; Bange, S.; Stiller, B.; Castellani, M.; Neher, D.; Kumke, M.; Hörhold, H.-H. Tuning of the Excited-State Properties and Photovoltaic Performance in PPV-Based Polymer Blends. J. Phys. Chem. C 2008, 112, 14607-14617.

78. Cho, N.S.; Hwang, D.-H.; Jung, B.-J.; Lim, E.; Lee, J.; Shim, H.-K. Synthesis, Characterization, and Electroluminescene of New Conjugated Polyfluorene Derivatives Containing Various Dyes as Comonomers. Macromolecules 2004, 37, 5265-5273.

79. Koetse, M.M.; Sweelssen, J.; Hoekerd, K.T.; Schoo, H.F.M.; Veenstra, S.C.; Kroon, J.M.; Yang, X.; Loos, J. Efficient polymer:polymer bulk heterojunction solar cells. Appl. Phys. Lett. 2006, 88, 83504:1-83504:3.

80. Sang, G.; Zou, Y.; Huang, Y.; Zhao, G.; Yang, Y.; Li, Y. All-polymer solar cells based on a blend of poly 3-(10-n-octyl-3-phenothiazine-vinylene)thiophene-co-2,5-thiophene and poly 1,4dioctyloxyl-p-2,5-dicyanophenylenevinylene. Appl. Phys. Lett. 2009, 94, 193302:1-193302:3.

81. Chochos, C.L.; Economopoulos, S.P.; Deimede, V.; Gregoriou, V.G.; Lloyd, M.T.; Malliaras, G.G.; Kallitsis, J.K. Synthesis of a Soluble $n$-Type Cyano Substituted Polythiophene Derivative: A Potential Electron Acceptor in Polymeric Solar Cells. J. Phys. Chem. C 2007, 111, 10732-10740.

82. Vijayakumar, C.; Saeki, A.; Seki, S. Optoelectronic Properties of Dicyanofluorene-Based $n$-Type Polymers. Chem. Asian J. 2012, 7, 1845-1852.

83. Cheng, Y.-J.; Yang, S.-H.; Hsu, C.-S. Synthesis of Conjugated Polymers for Organic Solar Cell Applications. Chem. Rev. 2009, 109, 5868-5923.

84. Cao, Y.; Lei, T.; Yuan, J.; Wang, J.-Y.; Pei, J. Dithiazolyl-benzothiadiazole-containing polymer acceptors: synthesis, characterization, and all-polymer solar cells. Polym. Chem. 2013, 4, 5228-5236.

85. Falzon, M.-F.; Zoombelt, A.P.; Wienk, M.M.; Janssen, R.A. Diketopyrrolopyrrole-based acceptor polymers for photovoltaic application. Phys. Chem. Chem. Phys. 2011, 13, 8931-8939.

86. Eo, M.; Lee, S.; Park, M.H.; Lee, M.H.; Yoo, S.; Do, Y. Vinyl-Type Polynorbornenes with Pendant PCBM: A Novel Acceptor for Organic Solar Cells. Macromol. Rapid Commun. 2012, 33, 1119-1125.

87. Eo, M.; Han, D.; Park, M.H.; Hong, M.; Do, Y.; Yoo, S.; Lee, M.H. Polynorbornenes with pendant PCBM as an acceptor for OPVs: Ring-opening metathesis versus vinyl-addition polymerization. Eur. Polym. J. 2014, 51, 37-44.

88. Chochos, C.L.; Govaris, G.K.; Kakali, F.; Yiannoulis, P.; Kallitsis, J.K.; Gregoriou, V.G. Synthesis, optical and morphological characterization of soluble main chain 1,3,4-oxadiazole copolyarylethers-Potential candidates for solar cells applications as electron acceptors. Polymer 2005, 46, 4654-4663.

89. Kymakis, E.; Koudoumas, E.; Franghiadakis, I. Bi-layer photovoltaic devices with PPQ as the electron acceptor layer. Sol. Energ. Mat. Sol. Cells 2006, 90, 1705-1714.

(C) 2014 by the authors; licensee MDPI, Basel, Switzerland. This article is an open access article distributed under the terms and conditions of the Creative Commons Attribution license (http://creativecommons.org/licenses/by/3.0/). 